\title{
Effect of $5-\mathrm{HT}_{6}$ Receptor Ligands Combined with
} Haloperidol or Risperidone on Antidepressant-I Anxiolytic-Like Behavior and BDNF Regulation in
Hippocampus and Prefrontal Cortex of Rats

\author{
Anna Wesołowska' \\ Joanna Rychtyk (D) \\ Joanna Gdula-Argasińska² \\ Katarzyna Górecka' \\ Natalia Wilczyńska-Zawal ${ }^{\prime}$ \\ Magdalena Jastrzębska- \\ Więsek' \\ Anna Partyka (iD) \\ 'Department of Clinical Pharmacy, \\ Faculty of Pharmacy, Jagiellonian \\ University Medical College, Kraków, \\ Poland; ${ }^{2}$ Department of Radioligands, \\ Faculty of Pharmacy, Jagiellonian \\ University Medical College, Kraków, \\ Poland
}

Background: The presence of depressive and anxiety symptoms in patients with schizophrenia may have an important impact on treatment and compliance. Hence, interventions addressing such comorbidity in schizophrenia should be explored. One target may be a serotonergic $5-\mathrm{HT}_{6}$ receptor $\left(5-\mathrm{HT}_{6} \mathrm{R}\right)$ since its ligands displayed antidepressant- and anxiolytic-like activities in preclinical experiments.

Methods: Acute and chronic (21 days) administration of haloperidol or risperidone in combination with a selective $5-\mathrm{HT}_{6} \mathrm{R}$ agonist (WAY-181187) or antagonist (SB-742457) to rats was performed for detecting antidepressant- and anxiolytic-like behaviors. In addition, the level of brain-derived neurotrophic factor (BDNF) protein and its gene expression in hippocampus and prefrontal cortex were determined.

Results: Both single and chronic administration of WAY-181187 with haloperidol produced antidepressant- and anxiolytic-like activities. SB-742457 did not provide full benefits in terms of improvement of haloperidol-induced adverse mood effects. However, the administration of SB-742457 with risperidone triggered its anxiolytic-like activity. Both 5-HT $\mathrm{R}_{6}$ ligands evoked no changes in haloperidol-induced effects on BDNF level. WAY-181187 induced repression of the $B D N F$ gene while SB-742457 increased its expression in both structures. 5- $\mathrm{HT}_{6} \mathrm{R}$ ligands, when combined with risperidone, did not change BDNF protein level and increased gene expression in the hippocampus, while they elevated BDNF level and potentiated gene expression in the prefrontal cortex.

Conclusion: The combined administration of WAY-181187 and haloperidol provided the greatest benefits, which were manifested by antidepressant-like effects and suppression of the anxiogenic-like properties. The combined administration of risperidone with both agonist and antagonist resulted only in an anxiolytic-like effect. It seems that the anxiolytic-like effects induced by haloperidol or risperidone with the addition of $5-\mathrm{HT}_{6} \mathrm{R}$ ligands are taskspecific. The data on BDNF protein and gene expression did not fully correspond with the behavioral outcomes, and thus it appears that other factors/mechanisms are involved in the observed antidepressant- and/or anxiolytic-like effects.

Keywords: schizophrenia, haloperidol, risperidone, $5-\mathrm{HT}_{6}$ receptor ligands, BDNF, rats

\section{Introduction}

Antipsychotic drugs (APDs) are a class of medications used in the treatment of psychosis, principally in schizophrenia as well as a range of other psychotic disorders. Currently, there are two classes of APDs: the first-generation APDs
Department of Clinical Pharmacy, Faculty of Pharmacy, Jagiellonian University Medical College, Medyczna 9 Street, Kraków, 30-688, Poland

$\mathrm{Tel} / \mathrm{Fax}+48 \quad 126205654$

Email annairena.partyka@uj.edu.pl 
(typical APDs) and the second-generation APDs (atypical APDs). Typical APDs are effective mainly against the positive symptoms of schizophrenia and fail to manage the negative or cognitive symptoms, while atypical APDs show broader efficacy in managing mood and negative symptoms. ${ }^{1}$ The latter ones are the mainstay in the treatment of bipolar disorder, in which they are used in combination with mood stabilizers. ${ }^{2}$ APDs, especially the atypical group, are also used in the treatment of anxietyrelated conditions including obsessive-compulsive disorder, panic disorder, or post-traumatic stress disorder. ${ }^{3,4}$ Several clinical reports have shown the beneficial effects of including atypical APDs in the ongoing treatment with antidepressant drugs or anxiolytics for better alleviation of mood impairments, particularly in the case of treatmentresistant depression ${ }^{5}$ or anxiety disorders, ${ }^{6,7}$ respectively.

According to the National Health Service Data Dictionary, adjunctive therapy is administered along with the main treatment to maximize its effectiveness. It is particularly applied in cases where the main disease, eg, schizophrenia, is accompanied by additional symptoms such as depressive ones or different types of anxiety. Depressive symptoms are seen in $50 \%$ of psychotic patients, ${ }^{8}$ while anxiogenic symptoms are observed in up to $65 \%$ of patients with schizophrenia. ${ }^{9-11}$ The presence of depression and anxiety disorders in patients with schizophrenia is gaining increasing interest because they have an important impact on the treatment and outcome in this group as well as their quality of life. APDs do not exhibit a strong antidepressant/anxiolytic effect, and the class of typical APDs that are still used by patients with schizophrenia may even worsen their symptoms of depression and/or anxiety. Hence, interventions addressing the comorbidity in schizophrenia should be supported and novel ways of combating comorbid disorders should be explored. Accordingly, there is a constant search for medicinal substances that could broaden the spectrum of the central activity of APDs, especially against the depressive and anxiety symptoms observed in patients with schizophrenia.

One target for such substances may be the serotonergic $5-\mathrm{HT}_{6}$ receptor $\left(5-\mathrm{HT}_{6} \mathrm{R}\right) .5-\mathrm{HT}_{6} \mathrm{R}$ is almost exclusively expressed in the cortical and limbic areas of the central nervous system (CNS), ie, regions associated with mood regulation, whereas outside CNS the density of this receptor seems to be negligible. ${ }^{12,13}$ Preclinical studies suggest the role of $5-\mathrm{HT}_{6} \mathrm{R}$ in depression and anxiety. Both agonists and antagonists showed antidepressant-like activity in forced swim test (FST) and tail suspension test (TST) in rats and mice. ${ }^{14-19}$ Transgenic $5-\mathrm{HT}_{6} \mathrm{R}$ knockout mice showed increased anxiety behaviors and the administration of specific antisense oligonucleotides induced anxiogenic-like effects in the elevated plus maze (EPM) and social interaction tests in rats. ${ }^{20,21}$ Similarly, both activation and blockade of 5 - $\mathrm{HT}_{6} \mathrm{R}$ produced anxiolytic-like activity in animal models of anxiety. For example, WAY-181187, the agonist of $5-\mathrm{HT}_{6} \mathrm{R}$, was active in the schedule-induced polydipsia test in rats, ${ }^{22}$ and SB-399885, the antagonist of $5-\mathrm{HT}_{6} \mathrm{R}$, showed antianxiety-like effects in four-plate test in mice and EPM and Vogel conflict drinking tests in rats. ${ }^{15,23}$ In the case of schizophrenia, the role of $5-\mathrm{HT}_{6} \mathrm{R}$ is poorly defined. Postmortem evidence demonstrates the reduced expression of $5-\mathrm{HT}_{6} \mathrm{R}$ in the hippocampus of patients with schizophrenia. ${ }^{24}$ Some APDs partially bind to $5-\mathrm{HT}_{6} \mathrm{R}$, and the receptor has been shown to be downregulated by prolonged administration of clozapine in rats. ${ }^{25}$ However, it is still unclear whether the observed reduction was due to schizophrenia itself or the repeated treatment with APD.

A large body of evidence indicates that the agonists and antagonists of $5-\mathrm{HT}_{6} \mathrm{R}$ can evoke identical responses in a number of behavioral paradigms. For instance, it has been demonstrated that both $5-\mathrm{HT}_{6} \mathrm{R}$ agonists and antagonists effectively improve cognitive dysfunction ${ }^{26,27}$ as well as possess antidepressant and anxiolytic properties. ${ }^{28}$ However, it is uncertain whether the agonists or antagonists of this receptor can best serve potential indications, such as depression and/or anxiety, and memory impairments. This uncertainty arises from the observation that both the agonists and antagonists of $5-\mathrm{HT}_{6} \mathrm{R}$ showed equivalent pharmacological potency and efficacy in animal models. Nonetheless, it should be noted that most of the presented results concerned the effects of $5-\mathrm{HT}_{6} \mathrm{R}$ ligands after acute administration. Thus, on the basis of preclinical studies, it can be concluded that $5-\mathrm{HT}_{6} \mathrm{R}$ ligands (both agonists and antagonists) may serve as an adjunct treatment for extending the therapeutic spectrum of APDs.

Considering the above-described issues, we decided to examine the combination of APD with an agonist and antagonist of $5-\mathrm{HT}_{6} \mathrm{R}$ in order to establish whether the $5-\mathrm{HT}_{6} \mathrm{R}$ ligands and which one of them would serve better in improving the action of neuroleptics toward mood regulation. Hence, the study aimed to test the acute and chronic (after 21 days of administration) effects of the chosen APDs-haloperidol and risperidone-administered separately or in combination with a selective $5-\mathrm{HT}_{6} \mathrm{R}$ agonist (WAY-181187) or antagonist 
(SB-742457) in rat models widely used for screening potential antidepressant (FST) and anxiolytic (EPM and Vogel conflict drinking tests) activities. There are few, if any, animal models sufficiently validated to discriminate among the various subtypes of anxiety disorders. The EPM is postulated to induce unconditioned fear due to heights and open spaces, which seems to be consistent with panic anxiety. ${ }^{29}$ Operant conflict procedures are pharmacologically isomorphic with the human state of generalized anxiety. ${ }^{30}$ Among these conditioned procedures, the Vogel conflict drinking test is of rather broad significance to clinical anxiety. ${ }^{31}$ Haloperidol and risperidone were selected for the study because they differ in their receptor profiles $\left(\mathrm{D}_{2}\right.$ preferential with no affinity to $5-\mathrm{HT}_{6} \mathrm{R}\left(\mathrm{K}_{\mathrm{i}}>5000 \mathrm{nM}\right)$ vs $5-\mathrm{HT}_{2 \mathrm{~A}} / \mathrm{D}_{2}$ preferential with low affinity to $\left.5-\mathrm{HT}_{6} \mathrm{R}\left(\mathrm{K}_{\mathrm{i}}=420 \mathrm{nM}\right)\right)^{32}$ and represent two different classes of APDs (typical vs atypical), which is reflected in their different effects observed in patients with schizophrenia in the clinic, including prodepressive activity vs limited effects on mood parameters.

As was reported previously, both WAY-181187 and SB-742457 were effective in different models that are commonly used for studying antidepressant- and anxiolytic-like activities after single administration. ${ }^{18,22,33}$ So far, infrequent or no data have been published demonstrating the effects of the agonists/antagonists of $5-\mathrm{HT}_{6} \mathrm{R}$ after prolonged administration. Therefore, the results presented in this paper may contribute to broadening the knowledge on the central selective action of both $5-\mathrm{HT}_{6} \mathrm{R}$ ligands.

Neurotrophins, particularly brain-derived neurotrophic factor (BDNF), take part in a wide variety of neural processes via their effects on synaptic plasticity and neuronal growth and differentiation. BDNF is also implicated in several psychiatric disorders, notably depression and schizophrenia. ${ }^{34,35}$ Therefore, we decided to investigate the involvement of hippocampal and cortical BDNF in the antidepressant- and anxiolyticlike effects of the studied substances and their combinations after the 21-day administration. To the best of our knowledge, this study is the first to conduct comparative experiments after acute and repeated administration of the chosen drug combinations to analyze their potential antidepressant and anxiolytic effects.

\section{Materials and Methods}

\section{Subjects}

Male Wistar rats, weighing 205-225 g $(\mathrm{N}=691)$, were obtained from the accredited animal facility at Jagiellonian University Medical College (Kraków, Poland). Upon arrival, the animals were housed in groups of four for a 6-day period in polycarbonate Makrolon type III cages (dimensions $26.5 \times 15 \times 42 \mathrm{~cm}$ ) in an environmentally controlled room (ambient temperature $22 \pm 2^{\circ} \mathrm{C}$; relative humidity $50-60 \%$; air changes $15-20$ times/h; light: dark cycle $12 \mathrm{~h}: 12 \mathrm{~h}$, lights on at 7:00). The following environmental enrichment materials were used: wooden blocks, paper tubs, paper stripes. Standard laboratory food (LSM-B) and filtered water were freely available to the rats. The animal cages were housed in a random order on the shelves. During the 6-day adaptation period, the animals were looked after by a person who did not participate in the experiments. The rats were randomly allocated into treatment groups by another investigator. All measurements have been done in a random order with the investigator blinded to the treatment received by rats.

On the day before the experiments, the equipment producing "white noise" was turned on for $30 \mathrm{~min}$, and the rats were weighed to the nearest $1 \mathrm{~g}$. Experimental groups (vehicle-treated groups (2-3) and haloperidol-, risperidone-, WAY-181187-, SB-742457-, haloperidol+WAY-181187-, risperidone+WAY-181187-, haloperidol+SB-742457-, risperidone+SB-742457-treated groups) consisted of 6-10 randomly selected animals, depending on the type of experiment. In acute experiments $\mathrm{N}=7-8$ animals per each treatment group were used except for the open field test (OFT), hot plate and free-drinking tests where $\mathrm{N}=6$. In chronic experiments $\mathrm{N}=9-10$ rats per each treatment group were used except for OFT where $\mathrm{N}=6$ (the detailed information is included in Supplementary Materials Tables S1-S11). All the experiments were performed between 9:00 and 14:00 on separate groups of animals by two observers unaware of the treatment applied. The animals were used only once. Immediately after each experiment, animals were sacrificed by decapitation by trained staff (when brain tissues were collected) or carbon dioxide (after acute behavioral tests). All the experimental procedures were carried out in a strict accordance with EU Directive 2010/63/EU and accordingly to Polish legal regulations ((Dz.U. 2015 pos. 266) were approved by the II Local Ethics Commission at the Institute of Pharmacology PAS in Kraków (Approval No. 107/2016). 
Moreover, in the studies, the 3R rule was applied in accordance with the relevant international and Polish regulations. In the event of a significant deterioration of animal health, we used early and humane endings of experimental procedures. Humane termination occurred when the animal had at least two symptoms such as convulsions, respiratory disturbance, movement disorder, immobility, lack of water and/or food intake, muscle relaxation, lack of touch response.

\section{Drugs and Treatment}

The following drugs were used in the study: haloperidol (TargetMol, Boston, MA, USA), risperidone (TargetMol), WAY-181187 (oxalate; Tocris Bioscience, Bristol, UK), and SB-742457 (TargetMol). APDs (haloperidol $0.5 \mathrm{mg} / \mathrm{kg}$ and risperidone $0.2 \mathrm{mg} / \mathrm{kg}$ ) were administered to rats at doses equivalent to the standard ones prescribed for patients with schizophrenia. The equivalent doses were calculated based on the body surface area as described previously by Nair et al. ${ }^{36}$ Selective $5-\mathrm{HT}_{6} \mathrm{R}$ ligands were chosen due to their similar affinity to $5-\mathrm{HT}_{6} \mathrm{R}$ (WAY-181187 $\mathrm{K}_{\mathrm{i}}=2.2 \mathrm{nM}^{22}$ and SB-742457 $\mathrm{K}_{\mathrm{i}}=9.6 \mathrm{nM}^{37}$ ), and for comparison reason, these ligands were administered at a dose of $3 \mathrm{mg} / \mathrm{kg}$; ie, a dose at which acute procognitive action for both compounds was observed in our earlier studies. ${ }^{38}$ The compounds were suspended in a $1 \%$ solution of Tween 80 (Sigma Aldrich, UK) before administration and were injected intraperitoneally (ip) in a volume of $2 \mathrm{~mL} / \mathrm{kg}$. In the case of acute treatment, haloperidol, risperidone, WAY-181187, and SB742457 were administered to the rats $60 \mathrm{~min}$ before the tests, whereas in the 21-day scheme of treatment, the compounds were administered once a day between 10:00 and 11:00 during 21 consecutive days, with the last injection 24 $\mathrm{h}$ before the tests. The control rats were injected with the vehicle according to the same schedule.

\section{Behavioral Studies Forced Swim Test}

This test was performed as described by Porsolt et $\mathrm{al}^{39}$ with the modifications proposed by Detke et al. ${ }^{40}$ On the first day of the experiment, each animal was gently placed in Plexiglas cylinders $(40-\mathrm{cm}$ high, $18-\mathrm{cm}$ in diameter) containing $30 \mathrm{~cm}$ of water, at a temperature of $23-25^{\circ} \mathrm{C}$, for $15 \mathrm{~min}$. On removal from water, the rat was placed for $30 \mathrm{~min}$ in a Plexiglas box under a $60-\mathrm{W}$ bulb to dry. On the following day ( $24 \mathrm{~h}$ later), the rat was placed again in the cylinder and the total duration of immobility, swimming, and climbing was recorded during the 5-min test period. The swimming behavior entailed active swimming motions, eg, horizontal movement around the cylinder. The climbing activity included upward-directed movements of the forepaws of the rat along the side of the swim chamber. The immobility was assigned when the rat showed no additional activity other than that necessary to keep its head above the water. Fresh water was used for each animal.

\section{Open Field Test}

This test was performed in a dark room using Motor Monitor System (Campden Instruments, Ltd., UK) consisting of two Smart Frame Open Field stations (dimensions $40 \times 40 \times 38 \mathrm{~cm}$ ) with $16 \times 16$ beams, located in sound-attenuating chambers and connected to PC software by control chassis. Each vehicle- or drug-injected animal was gently placed in the center of the station. The total distance covered by the animal in $5 \mathrm{~min}$ was recorded by the automated Motor Monitor System.

\section{Elevated Plus-Maze Test}

This test was performed as described by Pellow and File. ${ }^{41}$ The plus-maze apparatus (Campden Instruments Ltd., UK), an automated device used for this experiment, was made of durable, high-density, non-porous black plastic, elevated to a height of $50 \mathrm{~cm}$. It consisted of two open arms $(50 \times 10 \mathrm{~cm})$ and two closed arms $(50 \times 10 \mathrm{~cm}$, and 30 $\mathrm{cm}$ high walls), arranged in such a way that the two arms of each type were opposite to each other. The floor of the plus-maze was made of an infrared transparent material, and thus were no visible sensors. The apparatus was connected to PC software by control chassis. The experiment was conducted in a dark room, with only the center of the maze illuminated with a low-intensity light (30 lx measured at the maze level). During the experiment, each rat was gently placed in the center of the plus-maze, facing one of the closed arms, immediately after 5-min adaptation in a plastic black box (dimensions $60 \times 60 \times 35 \mathrm{~cm}$ ), to increase its overall activity in the EPM. During a 5-min test period, the number of entries of the rat into the closed and open arms and the time it spent in either type of arms were measured by an automated Motor Monitor System. The device counted an effective arm-entry when the four paws of the rat were into any arm. The maze was thoroughly cleaned after each trial. The number of open-arm entries of the rat, the total time spent by the rat in the open arms, and the percentages of these parameters were used as indications of anxiolytic-like activity. 


\section{Exploratory Activity Measured in the EPM}

To assess the influence of the tested compound on the general exploratory activity of rats and control possible changes within, the total number of entries (into open and closed arms) and the total distance covered by the rats during a 5-min test period (ie, the time equal to the observation period in the EPM test) were measured. The experiment was performed using the EPM apparatus described above.

\section{Vogel Conflict Drinking Test}

This test was performed as described by Vogel et $\mathrm{al}^{42}$ using Anxiety Monitoring System "Vogel test" (TSE Systems). The apparatus consisted of a polycarbonate cage (dimensions $26.5 \times 15 \times 42 \mathrm{~cm}$ ), equipped with a grid floor made of stainless steel bars and a drinking bottle containing tap water. The two experimental chambers were connected to PC software by control chassis and a device that generates electric shocks. In the "conditional" model, an electric shock was applied as a noxious stimulus. The testing procedure consisted of a 2-day habituation/adaptation and the exact test. On the first day of the experiment, the rats were adapted to the test chamber for 10-min (adaptation period), during which they had free access to the drinking bottle, followed by a 24-h water deprivation period. Afterward, the rats were allowed free access to water for 30-min (freedrinking session) in their home cages. This protocol of a 24-h deprivation and adaptation period was repeated on the second day. On the third day, the animals were placed again in the test chamber $60 \mathrm{~min}$ after the administration of the vehicle or the tested compounds and were allowed free access to the drinking bottle for $5 \mathrm{~min}$. Recording of data started immediately after the first lick, and after every 20 licks, the rats were punished with an electric shock $(0.5 \mathrm{~mA}$, lasting $1 \mathrm{~s})$. The impulses were released via the spout of the drinking bottle. The number of shocks received by an animal during the 5-min experimental session was recorded automatically and used as an indication of the anti-conflict activity.

\section{Hot Plate and Free-Drinking Tests}

To exclude the possibility of drug-induced changes in shock sensitivity or an increasing influence on thirst drive which can lead to false-positive results in the Vogel conflict drinking test, stimulus threshold and water consumption during the free-drinking session were determined for separate groups of rats. In both studies, the rats were manipulated similarly to the Vogel conflict drinking test, including two 24-h water deprivation periods separated by 10 -min adaptation session in experimental cages and 30-min of water availability in their home cages. In the free-drinking test, each animal was allowed to drink freely from the drinking bottle and the amount of water $(\mathrm{g})$ consumed during $5 \mathrm{~min}$ was recorded. The pain threshold was evaluated in rats using the hot plate test. ${ }^{43}$ The plate (Commat Ltd, Turkey) was enclosed in a transparent Plexiglass cylinder (35-cm high) to keep the animal on the heated surface of the plate. The latency to pain reaction (licking of a hind paw or jumping) was measured when the rat was placed on the hot plate ( 52.5 $\pm 0.5^{\circ} \mathrm{C}, 19-\mathrm{cm}$ diameter). The rat was removed from the plate immediately upon a visible pain reaction or if no response was observed within $30 \mathrm{~s}$.

\section{Ex-vivo Biochemical Studies Tissue Collection}

Animals in all treatment groups were sacrificed by rapid decapitation immediately after the behavioral tests. For protein analysis and quantitative reverse transcription-polymerase chain reaction (RT-qPCR), the brains of rats were rapidly removed and the hippocampus and prefrontal cortex were dissected out on an ice-cold glass plate. The tissues were frozen in dry ice and stored at $-80^{\circ} \mathrm{C}$ until required.

\section{Western Blot Analysis}

The hippocampus and prefrontal cortex samples were homogenized in T-PER mammalian protein extraction reagent (Thermo Fisher Scientific, Waltham, MA, USA) with protease (Merck Millipore, Burlington, MA, USA) and phosphatase inhibitors (Cayman Chemical, Ann Arbor, MI, USA). The concentration of proteins was determined using the Bradford assay. The aliquots $(40 \mu \mathrm{g})$ were solubilized in Laemmli buffer with $2 \%$ 2-mercaptoethanol and were subjected to $10 \%$ sodium dodecyl sulfate-polyacrylamide gel electrophoresis. Anti-BDNF (15kDa, 1:500 dilution) and anti- $\beta$-actin (1:1000 dilution) (Thermo Fisher Scientific) were used as primary antibodies, while anti rabbit IgG (horse radish peroxidase) (1:2000 dilution; Thermo Fisher Scientific) was used as the secondary antibody. Proteins were detected using Clarity Western ECL Luminol Substrate (Bio-Rad, Hercules, CA, USA). Chemi Doc Camera with Image Lab 5.2.1 software (Bio-Rad) was used to quantify the integrated optical density of the bands. 


\section{Quantitative Real-Time PCR}

RNA was extracted from tissues using RNA Isolation kit (Thermo Fisher Scientific). After evolution of quantity and quality, its concentration was normalized to $15 \mathrm{ng} / \mu \mathrm{L}$. Reverse transcription was performed with High-Capacity Reverse Transcription Kit (Life Technologies, Grand Island, NY, USA). A qPCR 96-well reaction plate was used for the process with TaqMan (Life Technologies) primers and probes for BDNF (Rn02531967_s1), according to the manufacturer's protocol, on Applied Biosystems ${ }^{\circledR} 7500$ Fast Real-Time PCR Instrument (Applied Biosystems, Foster City, CA, USA). Gapdh (Rn01775763_g1) and Tbp (Rn01455646_m1) were selected as endogenous control genes based on the pilot experiment. Relative expression was calculated using the $\Delta \Delta \mathrm{Cq}$ method.

\section{Statistical Analysis}

All the data are presented as mean \pm standard error of mean (SEM). The statistical significance of the results was evaluated by a two-way analysis of variance, followed by
Bonferroni's comparison test. A $p$-value of $<0.05$ was considered significant.

\section{Results}

\section{Behavioral Studies}

Influence of WAY-I8II87 or SB-742457 on the

Effects of Haloperidol and Risperidone After Single

\section{Administration in Modified FST in Rats}

WAY-181187 significantly decreased the immobility time $(\mathrm{p}<0.01)$ and increased the climbing time $(\mathrm{p}<0.001)$ of rats, while no significant influence of SB-742457 was noted on the parameters measured during FST. Haloperidol significantly increased the immobility time $(\mathrm{p}<0.05)$ but had no significant influence on the climbing time of rats. Risperidone did not modify the immobility time or climbing time of rats in FST in comparison to the vehicle-treated group. The combined treatment with haloperidol and WAY-181187 significantly shortened the immobility time of rats in comparison to the haloperidol-treated group $(\mathrm{p}<0.05)$, while SB-742457 had no impact on the prodepressive effect of haloperidol in rats in FST. Neither
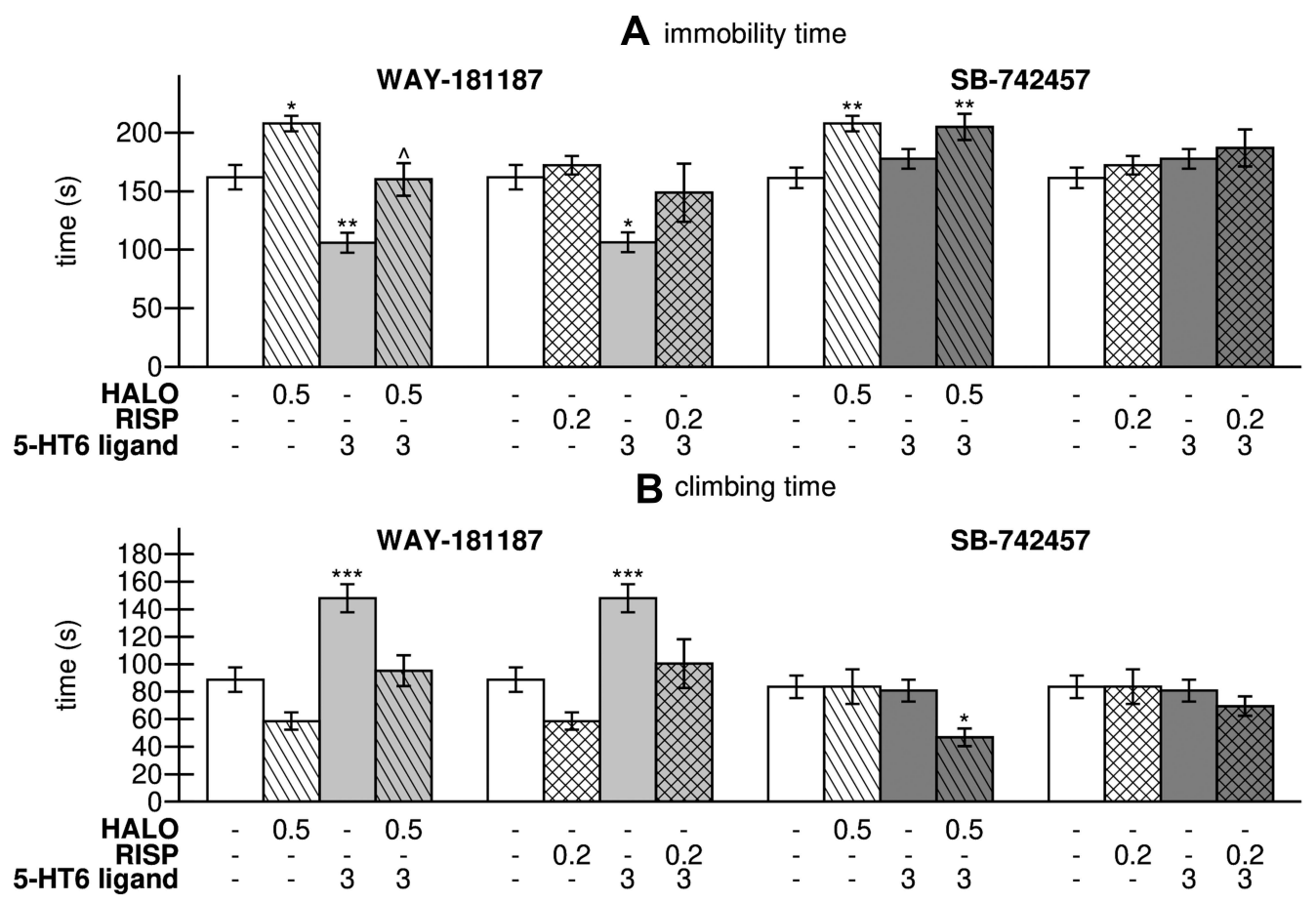

Figure I Effects of acute administration of haloperidol, risperidone, WAY-I8I I87, and SB-742457, alone and in combinations, on immobility time (A) and climbing time (B) of rats in modified FST.

Notes: Data are presented as the mean \pm SEM; ${ }^{*} p<0.05,{ }^{* *} p<0.01$, ${ }^{* * *} \mathrm{p}<0.001$ vs respective control group, ${ }^{\wedge} \mathrm{p}<0.05$ vs respective APD-treated group (two-way ANOVA is followed by the Bonferroni's post hoc test).

Abbreviations: HALO, haloperidol; RISP, risperidone. 
WAY-181187 nor SB-742457 influenced the effect of risperidone in rats in the test (Figure 1, Supplementary Table S1).

Influence of WAY-I8II87 or SB-742457 on the Effects of Haloperidol and Risperidone After Single Administration on Spontaneous Locomotor Activity in OFT in Rats

After the single administration of WAY-181187 as well as SB-742457, no significant effects were observed on the parameters measured in the OFT in rats in comparison to the respective vehicle group. Similarly, when administered alone, haloperidol and risperidone did not significantly change the locomotor activity of rats in the test. The co-administration of haloperidol with WAY-181187 caused a significant decrease in the total distance covered by rats during the test in comparison to both vehicle-treated $(\mathrm{p}<0.0001)$ and haloperidoltreated groups $(\mathrm{p}<0.0001)$. The addition of SB-742457 to haloperidol also resulted in a significant reduction in the total distance covered by rats, when compared to the control group ( $\mathrm{p}<0.01)$. On the other hand, after the combined administration of risperidone and WAY-181187 or SB-742457, no significant effects were observed on the parameter measured in OFT in rats in comparison to the respective vehicle as well as risperidone group (Table 1, Supplementary Table S3).

Table I Effects of Acute Administration of Haloperidol, Risperidone, WAY-18II87, and SB-742457, Alone and in Combinations, on the Locomotor Activity of Rats (OFT)

\begin{tabular}{|l|c|}
\hline Treatment (mg/kg) & Total Distance Moved (cm)/5 Min \\
\hline Vehicle & $2003.0 \pm 67.4$ \\
HALO (0.5) & $1539.6 \pm 258.8$ \\
WAY-I8II87 (3.0) & $2046.7 \pm 135.2$ \\
HALO (0.5) + WAY (3.0) & $354.6 \pm 105.9$ d,D \\
Vehicle & $2003.0 \pm 67.4$ \\
RISP $(0.2)$ & $1720.6 \pm 59.8$ \\
WAY-I8II87 (3.0) & $2046.7 \pm 135.2$ \\
RISP $(0.2)+$ WAY (3.0) & $1970.8 \pm 34.7$ \\
Vehicle & $2003.0 \pm 67.4$ \\
HALO (0.5) & $1539.6 \pm 258.8$ \\
SB-742457 (3.0) & $1997.7 \pm 176.6$ \\
HALO (0.5) + SB (3.0) & $1201.7 \pm 230.5$ \\
Vehicle & $2003.0 \pm 67.4$ \\
RISP $(0.2)$ & $1720.6 \pm 59.8$ \\
SB-742457 (3.0) & $1997.7 \pm \mid 76.6$ \\
RISP $(0.2)+$ SB (3.0) & $1888.3 \pm|3| .8$ \\
\hline
\end{tabular}

Notes: Data are presented as the mean \pm SEM; ${ }^{b} p<0.01,{ }^{d} p<0.0001$ vs respective control group; ${ }^{\mathrm{D}}<0.000 \mathrm{l}$ vs respective APD-treated group (two-way ANOVA is followed by the Bonferroni's post hoc test).

Abbreviations: HALO, haloperidol; RISP, risperidone; WAY, WAY-18। 187; SB, SB742457.
Influence of WAY-I8II87 or SB-742457 on the Effects of Haloperidol and Risperidone After 2I-Day Administration in Modified FST in Rats

After repeated administration, neither WAY-181187 nor SB-742457 changed the behavior of rats in FST. Haloperidol increased the immobility time $(\mathrm{p}<0.05)$ and shortened the climbing time $(\mathrm{p}<0.05)$ in a statistically significant manner, while risperidone had no influence on the recorded parameters. The addition of WAY181187 to haloperidol resulted in a significant shortening of the immobility time in comparison to both control $(p<0.05)$ and haloperidol-treated groups $(p<0.0001)$ as well as an increase in the climbing time in comparison to haloperidol-treated group $(\mathrm{p}<0.05)$. SB-742457 did not change the effect of haloperidol on the immobility time, but significantly increased the climbing time in comparison to the haloperidol-treated group $(\mathrm{p}<0.05)$. Neither the $5-\mathrm{HT}_{6} \mathrm{R}$ agonist nor the antagonist influenced the effect of risperidone in rats in FST (Figure 2, Supplementary Table S2).

Influence of WAY-18II87 or SB-742457 on the Effects of Haloperidol and Risperidone After 2I-Day Administration on Spontaneous Locomotor Activity in OFT in Rats

None of the tested compounds, when administered alone and chronically, changed the locomotor activity of rats in OFT. Similar to the observation with the addition of SB-742457 to haloperidol $(\mathrm{p}<0.05)$ and risperidone $(\mathrm{p}<0.05)$, WAY-181187 administered with haloperidol significantly increased the total distance covered by rats in OFT in comparison to the control group $(p<0.05)$. In contrast, the combined administration of risperidone and WAY-181187 did not influence the locomotor activity of animals (Table 2, Supplementary Table S3).

Influence of WAY-I8I I87 or SB-742457 on the Effects of Haloperidol and Risperidone on Rats' Behavior After Acute Administration in the EPM Test When administered alone, WAY-181187 and SB-742457 had no effect on the parameters recorded in the EPM test. Haloperidol significantly shortened the time spent by rats in the open arms $(p<0.001)$, decreased the percentage of time spent in the open arms $(p<0.01)$, and reduced the number and percentage of open-arm entries $(p<0.0001$ and $\mathrm{p}<0.5$, respectively). On the other hand, risperidone did not change the values of parameters measured in the EPM test, except in combination with SB-742457 where 

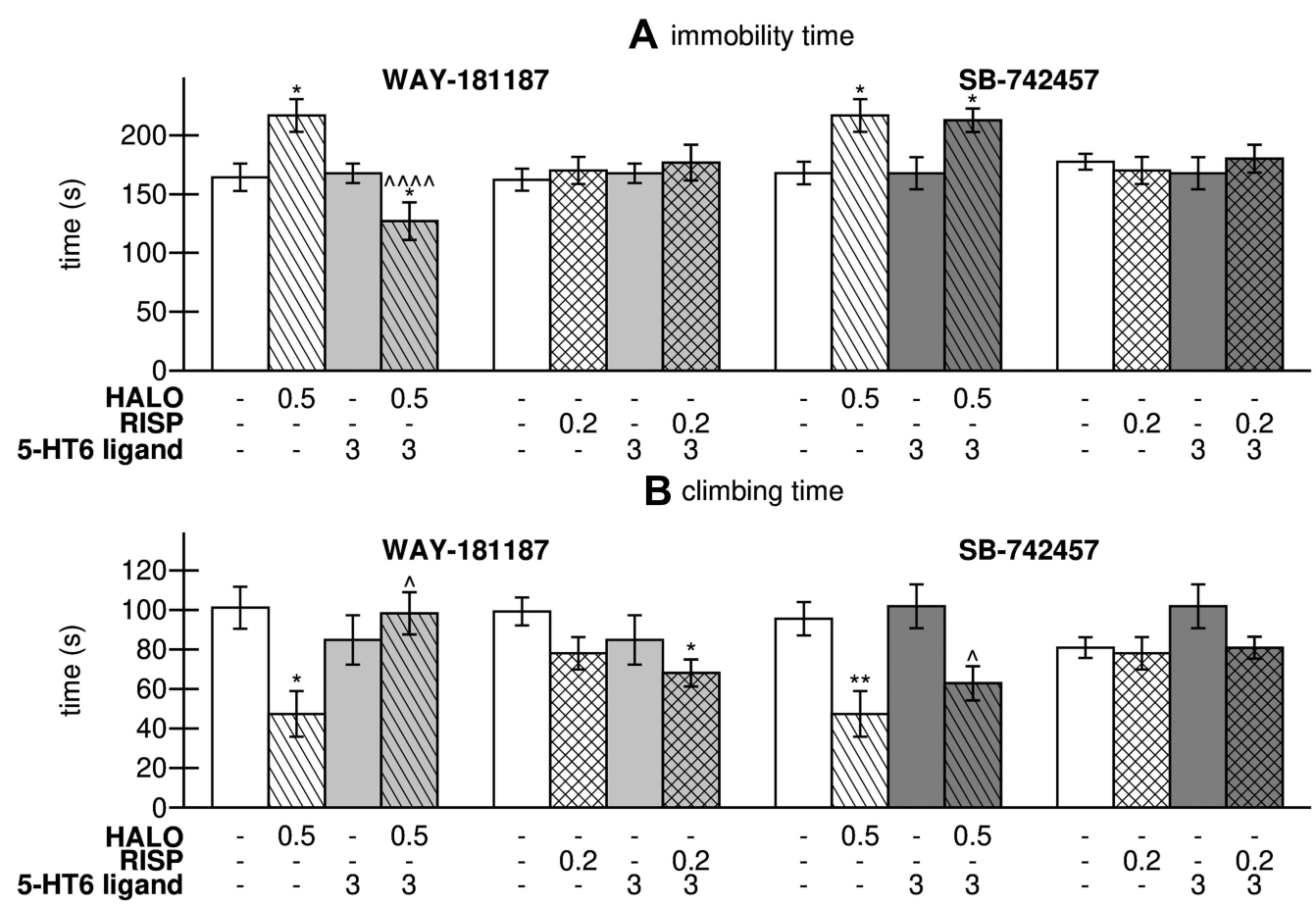

Figure 2 Effects of 2 I-day administration of haloperidol, risperidone, WAY-18I I87, and SB-742457, alone and in combinations, on immobility time (A) and climbing time (B) of rats in FST.

Notes: Data are presented as the mean $\pm \mathrm{SEM} ;{ }^{*} \mathrm{p}<0.05,{ }^{* *} \mathrm{p}<0.01$ vs respective control group, ${ }^{\wedge} \mathrm{p}<0.05,{ }^{\wedge \wedge \wedge} \mathrm{p}<0.000 \mathrm{I}$ vs respective APD-treated group (two-way ANOVA is followed by the Bonferroni's post hoc test).

Abbreviations: HALO, haloperidol; RISP, risperidone.

the drug significantly decreased the number of entries into the open arms $(\mathrm{p}<0.01)$ in comparison to the control group. WAY-181187 had no significant impact on the effects of haloperidol in the EPM test, while the addition of SB-742457 resulted in an increase in all the recorded parameters; however, a statistically significant difference in means was noted only in the percentage of time spent in the open arms in comparison to the haloperidol-treated group ( $<<0.01$ ). WAY-181187 or SB-742457 did not significantly change the effects of risperidone; however, both these $5-\mathrm{HT}_{6} \mathrm{R}$ ligands caused a reduction in all the measured parameters in comparison to the risperidone-treated group, which revealed the significant anxiogenic effects of these combinations compared to the vehicle: co-administration of risperidone and WAY-181187 significantly decreased the number of entries into the open arms $(p<0.05)$, while the addition of SB-742457 resulted in a significant reduction in time spent by rats in the open arms $(p<0.05)$, the percentage of time spent in the open arms $(p<0.05)$ and the number of entries into the open arms $(p<0.0001)$ (Figure 3, Supplementary Table S4).
Influence of WAY-18I I 87 or SB-742457 on the Effects of Haloperidol and Risperidone After Single Administration on Exploratory Activity of Rats Measured in EPM

No significant effects on exploratory activity of rats were observed when WAY-181187 or risperidone was administered alone. SB-742457 administered alone significantly increased the total distance covered by rats in the EPM $(p<0.05)$. Haloperidol significantly decreased the exploratory activity of the animals in comparison to the control group $(p<0.0001)$. Similarly, risperidone significantly decreased the exploratory activity of rats, but only when it was administered in combination with SB-742457 $(p<0.01)$. The addition of WAY-181187 or SB-742457 to haloperidol resulted in a significant reduction in the exploratory activity of rats in comparison to the control $(p<0.0001)$. Combined administration of SB-742457 and risperidone significantly decreased both parameters related to the exploratory activity of rats $(\mathrm{p}<0.01)$, whereas in the case of combination of WAY-181187 and risperidone no significant changes in the exploratory behavior of rats were noticed (Table 3, Supplementary Table S5). 
Table 2 Effects of 21-Day Administration of Haloperidol, Risperidone, WAY-181187, and SB-742457, Alone and in Combinations, on the Locomotor Activity of Rats in OFT

\begin{tabular}{|l|c|}
\hline Treatment (mg/kg) & Total Distance Moved (cm)/5 Min \\
\hline Vehicle & $2379.1 \pm 102.5$ \\
HALO (0.5) & $2451.7 \pm 219.0$ \\
WAY-I8II87 (3.0) & $2549.3 \pm 147.2$ \\
HALO (0.5) + WAY (3.0) & $3044.2 \pm 101.6^{\mathrm{a}}$ \\
Vehicle & $2379.1 \pm 102.5$ \\
RISP $(0.2)$ & $2359.0 \pm 170.8$ \\
WAY-I8II87 (3.0) & $2549.3 \pm 147.2$ \\
RISP (0.2) + WAY (3.0) & $2394.2 \pm 264.1$ \\
Vehicle & $2369.6 \pm 146.0$ \\
HALO (0.5) & $2451.7 \pm 219.0$ \\
SB-742457 (3.0) & $2986.8 \pm 183.3$ \\
HALO (0.5) + SB (3.0) & $3179.8 \pm 131.6^{\mathrm{a}}$ \\
Vehicle & $2369.6 \pm 146.0$ \\
RISP $(0.2)$ & $2359.0 \pm 170.8$ \\
SB-742457 (3.0) & $2986.8 \pm 183.3$ \\
RISP (0.2) + SB (3.0) & $3159.3 \pm 141.2^{\mathrm{a}, \mathrm{A}}$ \\
\hline
\end{tabular}

Notes: Data are presented as the mean \pm SEM; ${ }^{a} \mathrm{p}<0.05$ vs respective control group; ${ }^{A} p<0.05$ vs respective APD-treated group (two-way ANOVA is followed by the Bonferroni's post hoc test).

Abbreviations: HALO, haloperidol; RISP, risperidone; WAY, WAY-I8I I87; SB, SB742457.

Influence of WAY-I8I I 87 or SB-742457 on the Effects of Haloperidol and Risperidone on Rats' Behavior After 2I-Day Administration in the EPM Test

As shown in Figure 4, the 21-day administration of both WAY-181187 and SB-742457 did not influence the behavior of rats in the EPM test. Similarly, haloperidol given alone did not significantly change the recorded parameters. Risperidone caused a remarkable decrease only in the percentage of time spent in the open arms in comparison to the control group $(\mathrm{p}<0.05)$. The addition of WAY181187 to haloperidol or risperidone had no significant effect on the activity of these APDs; however, an insignificant increase was noted in all the measured values in comparison to the respective APD-treated groups. The addition of SB-742457 to haloperidol caused a significant increase in the time $(\mathrm{p}<0.001)$ and percentage of time $(p<0.001)$ spent by the rats in the open arms as well as in the number of entries of rats into the open arms $(p<0.05)$, while an insignificant increase was observed in the percentage of entries of rats into the open arms. Similarly, co-administration of SB-742457 with risperidone led to a significant increase the time $(\mathrm{p}<0.01)$ and percentage of time $(p<0.01)$ spent by the rats in the open arms as well as in the percentage of entries of rats into the open arms $(p<0.01)$, but an insignificant increase was observed in the number of entries of the animals into the open arms (Figure 4, Supplementary Table S6).

Influence of WAY-18II87 or SB-742457 on the Effects of Haloperidol and Risperidone After 2I-Day Administration on Exploratory Activity of Rats Measured in EPM

After repeated, 21-day administration, only haloperidol given alone significantly shortened the total distance covered by the rats measured during the EPM test $(\mathrm{p}<0.05)$. Other tested compounds, administered either separately or in combinations, did not change the exploratory activity of rats in EPM (Table 4, Supplementary Table S7).

Influence of WAY-I8I I 87 or SB-742457 on the Effects of Haloperidol and Risperidone After Single Administration in Vogel Conflict Drinking Test in Rats When administered acutely and separately, WAY-181187, SB-742457, haloperidol, and risperidone had no significant effects on the number of shocks and licks recorded in the Vogel test. However, combined administration of WAY181187, but not SB-742457, with risperidone caused a significant increase in the number of shocks accepted by the rats $(\mathrm{p}<0.001$ versus vehicle- and risperidone-treated groups) as well as the number of licks in comparison to both control $(\mathrm{p}<0.001)$ and risperidone-treated $(\mathrm{p}<0.0001)$ groups. The addition of SB-742457 to haloperidol or risperidone did not influence the effects of APD (Figure 5, Supplementary Table S8).

The concomitant administration of haloperidol and WAY-181187, which was found to be effective in the Vogel conflict drinking test, had no significant effect on the pain reaction time of rats in the hot plate test and did not change the amount of water consumed by deprived rats during the 5-min experimental session (Supplementary Table S10).

Influence of WAY-I8II87 or SB-742457 on the Effects of Haloperidol and Risperidone After 2I-Day Administration in Vogel Conflict Drinking Test in Rats

As shown in Figure 6, a significant increase was observed in the number of licks after repeated co-administration of haloperidol and WAY-181187 when compared to the haloperidol-treated group $(\mathrm{p}<0.05)$. In other cases, the administered treatment did not significantly change the parameters recorded in the Vogel conflict drinking test (Figure 6, Supplementary Table S9). 

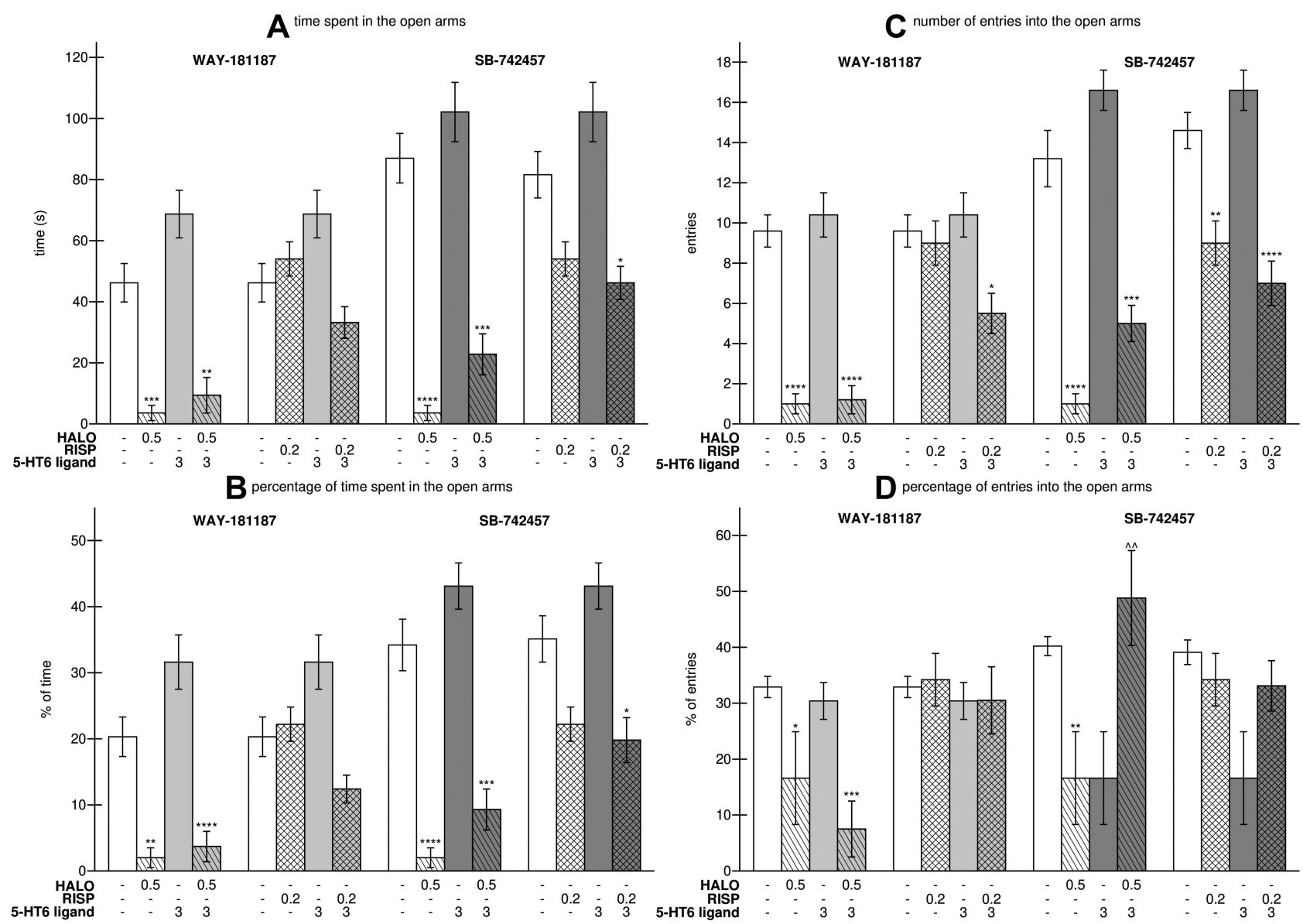

Figure 3 Effects of acute administration of haloperidol, risperidone, WAY-18I I87, and SB-742457, alone and in combinations, on the time (A) and percentage of time (B) spent in the open arms, entries (C) and percentage of entries (D) into the open arms in the EPM test in rats.

Notes: Data are presented as the mean \pm SEM; ${ }^{*} \mathrm{p}<0.05$, ${ }^{* *} \mathrm{p}<0.0 \mathrm{I}$, ${ }^{* * *} \mathrm{p}<0.00 \mathrm{I}$, ${ }^{* * * *} \mathrm{p}<0.000$ I vs respective control group (two-way ANOVA is followed by the Bonferroni's post hoc test).

Abbreviations: HALO, haloperidol; RISP, risperidone.

\section{Ex-vivo Biochemical Studies}

Influence of WAY-I8II87 or SB-742457 on the Effects of Haloperidol and Risperidone on BDNF Protein Level and BDNF Gene Expression in the Hippocampus and Prefrontal Cortex of Rats After 21 -Day Administration

As shown in Figure 7, a significant increase in the level of BDNF protein compared to the control group was observed in the hippocampus of rats subjected to chronic administration of WAY-181187 $(\mathrm{p}<0.01)$. However, no significant changes in hippocampal $B D N F$ gene expression were observed after the administration of the 5- $\mathrm{HT}_{6} \mathrm{R}$ agonist. Haloperidol, when given alone, had no effect on the level of BDNF protein, but caused a significant increase in $B D N F$ gene expression in the hippocampus of rats $(\mathrm{p}<0.0001)$. Co-administration of haloperidol and WAY-181187 did not significantly affect the level of BDNF protein in the rat hippocampus, but significantly repressed the $B D N F$ gene in comparison to both control $(\mathrm{p}<0.0001)$ and haloperidol-treated $(p<0.0001)$ groups. The administration of risperidone significantly increased the level of BDNF protein $(\mathrm{p}<0.05)$ but decreased the $B D N F$ gene expression $(p<0.0001)$ in the hippocampus of rats in comparison to the control group. The combined administration of risperidone and WAY-181187 did not change the hippocampal level of BDNF protein as compared to the control group and caused significant repression of the BDNF gene in comparison to both control $(\mathrm{p}<0.0001)$ and risperidone-treated $(\mathrm{p}<0.0001)$ groups (Figure 7, Supplementary Table S11).

SB-742457 administered alone significantly increased the hippocampal level of BDNF protein $(\mathrm{p}<0.001)$ as well as the $B D N F$ gene expression $(\mathrm{p}<0.0001)$. A significant increase in the level of BDNF protein was noted after 
Table 3 Effects of Acute Administration of Haloperidol, Risperidone, WAY-181187, and SB-742457, Alone and in Combinations, on the Total Exploration of Rats in the EPM Test

\begin{tabular}{|l|c|c|}
\hline Treatment (mg/kg) & Total Entries & Total Distance (cm) \\
\hline Vehicle & $30.2 \pm 2.7$ & $4272.6 \pm 233.0$ \\
HALO (0.5) & $6.0 \pm 1.6^{\mathrm{d}}$ & $1309.2 \pm 181.2^{\mathrm{d}}$ \\
WAY-I8II87 (3.0) & $34.5 \pm 2 . .^{\mathrm{d}}$ & $4467.5 \pm 139.4$ \\
HALO (0.5) + WAY (3.0) & $6.9 \pm 2.6^{\mathrm{d}}$ & $1406.0 \pm 362.2^{\mathrm{d}}$ \\
Vehicle & $30.2 \pm 2.7$ & $4272.6 \pm 233.0$ \\
RISP (0.2) & $28.9 \pm 3.4$ & $3865,6 \pm 201.8$ \\
WAY-I8II87 (3.0) & $34.5 \pm 2.2$ & $4467.5 \pm 139.4$ \\
RISP (0.2) + WAY (3.0) & $20.7 \pm 3.7$ & $4627.7 \pm 304.8$ \\
Vehicle & $32.3 \pm 2.6$ & $4303.3 \pm 207.7$ \\
HALO (0.5) & $6.0 \pm 1.6^{\mathrm{d}}$ & $1309.2 \pm 181.2^{\mathrm{d}}$ \\
SB-742457 (3.0) & $41.7 \pm 2.0$ & $5324.4 \pm 162.1^{\mathrm{a}}$ \\
HALO (0.5) + SB (3.0) & $11.9 \pm 3.2^{\mathrm{d}}$ & $2114.6 \pm 297.3^{\mathrm{d}}$ \\
Vehicle & $38.4 \pm 3.4$ & $4791.5 \pm 156.5$ \\
RISP (0.2) & $28.9 \pm 3.4$ & $3865,6 \pm 201.8^{\mathrm{b}}$ \\
SB-742457 (3.0) & $41.7 \pm 2.0$ & $5324,4 \pm 162.1^{\mathrm{a}}$ \\
RISP (0.2) + SB (3.0) & $22.1 \pm 3.0^{\mathrm{b}}$ & $3869.4 \pm 271.2^{\mathrm{a}}$ \\
\hline
\end{tabular}

Notes: Data are presented as the mean \pm SEM; ${ }^{a} p<0.05,{ }^{b} p<0.01,{ }^{d} p<0.01$ vs respective control group (two-way ANOVA is followed by the Bonferroni's post hoc test).

Abbreviations: HALO, haloperidol; RISP, risperidone; WAY, WAY-181 I87; SB, SB742457.

concomitant administration of SB-742457 and haloperidol compared to control $(\mathrm{p}<0.05)$. Similarly, addition of the $5-\mathrm{HT}_{6} \mathrm{R}$ antagonist to risperidone resulted in a slight increase in the level of BDNF protein in comparison to the group treated with APD alone but the effect was not statistically significant (Figure 7A). The addition of SB742457 to haloperidol caused a significant increase in hippocampal $B D N F$ gene expression in comparison to both control $(\mathrm{p}<0.0001)$ and haloperidol-treated $(\mathrm{p}<0.0001)$ groups. In contrast, significant repression of $B D N F$ gene was noted in the hippocampus of rats that received the $5-\mathrm{HT}_{6} \mathrm{R}$ antagonist and risperidone compared to the control group $(\mathrm{p}<0.0001)$, and the effect was significantly weaker when compared to the risperidone-treated group $(\mathrm{p}<0.0001)$ (Figure $7 \mathrm{~B})$.

Both WAY-181187 and SB-742457 significantly elevated the level of BDNF protein $(\mathrm{p}<0.001$ and $\mathrm{p}<0.01$, respectively) as well as $B D N F$ gene expression $(\mathrm{p}<0.0001$ and $\mathrm{p}<0.01$, respectively) in the prefrontal cortex of rats in comparison to the respective control groups (Figure 8, Supplementary Table S11). A similar effect was observed after haloperidol administration $(\mathrm{p}<0.01$ and $\mathrm{p}<0.0001$, for BDNF protein and $B D N F$ gene, respectively), while risperidone administration did not cause any change in the level of BDNF protein or BDNF gene expression. The addition of WAY-181187 to haloperidol resulted in significant repression of $B D N F$ gene $(\mathrm{p}<0.0001$ vs haloperidol-treated group), whereas the gene was significantly activated after combined administration of the $5-\mathrm{HT}_{6} \mathrm{R}$ agonist and risperidone $(\mathrm{p}<0.0001$ vs risperidonetreated group). The addition of WAY-181187 to haloperidol did not significantly affect the level of BDNF protein in the rat prefrontal cortex in comparison to haloperidoltreated group, while co-administration of the $5-\mathrm{HT}_{6} \mathrm{R}$ agonist with risperidone increased the level of BDNF protein $(\mathrm{p}<0.01$ vs vehicle- and risperidone-treated groups). SB-742457 co-administered with haloperidol did not influence its effects on BDNF protein level and gene expression. On the other hand, a significant increase in the level of BDNF protein $(\mathrm{p}<0.001)$ and $B D N F$ gene expression $(\mathrm{p}<0.001)$ was observed after the concomitant administration of SB-742457 and risperidone in comparison to risperidone-treated group (Figure 8B).

\section{Discussion}

In the present study, haloperidol administered both acutely and repeatedly caused depressive-like symptoms in FST in rats as well as an anxiogenic-like effect in EPM. No significant impact was observed in the Vogel conflict drinking test. The addition of WAY-181187 to haloperidol alleviated the prodepressive-like activity of the APD after single administration and induced an antidepressant-like effect after repeated administration in FST. Furthermore, chronic administration of $5-\mathrm{HT}_{6} \mathrm{R}$ agonist with haloperidol resulted in a clear, although insignificant, mitigation of the anxiogenic-like effect of the APD in EPM and in the Vogel test. No significant influence of SB-742457 on prodepressive-like properties of haloperidol was noted in FST after single or 21-day administration. However, the $5-\mathrm{HT}_{6} \mathrm{R}$ antagonist attenuated the anxiogenic-like effect of this APD in the EPM test after both single and chronic administration, and in the Vogel conflict drinking test after repeated administration. In contrary to haloperidol, the atypical APD, risperidone, did not affect the behavior of animals in FST and did not show any significant effects in the EPM test as well as in the Vogel conflict drinking test. The addition of WAY-181187 or SB-742457 to risperidone in both single and multiple administration did not influence the effect of APD administered alone in FST. Similarly, the addition of WAY-181187 to risperidone, after both acute and chronic administration, produced no anxiolytic-like effect in the EPM test but resulted in 

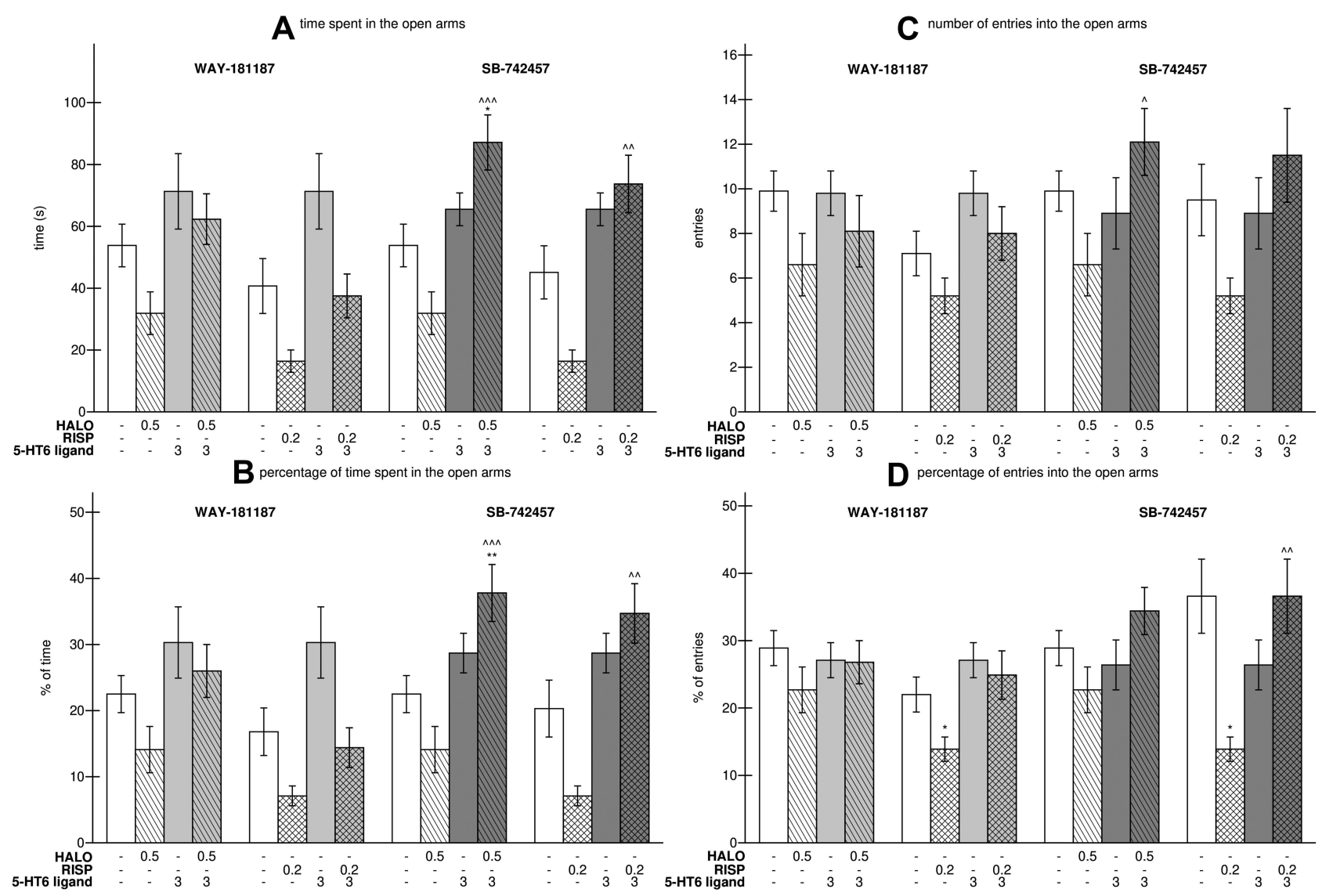

Figure 4 Effects of 2I-day administration of haloperidol, risperidone, WAY-18II87, and SB-742457, alone and in combinations, on time (A) and percentage of time (B) spent in the open arms, entries (C) and percentage of entries (D) in the EPM test in rats.

Notes: Data are presented as the mean \pm SEM; ${ }^{*} \mathrm{p}<0.05$, $* * \mathrm{p}<0.01$ vs respective control group, ${ }^{\wedge} \mathrm{p}<0.05,{ }^{\wedge \wedge} \mathrm{p}<0.01,{ }^{\wedge \wedge \wedge} \mathrm{p}<0.00 \mathrm{I}$ vs respective $A \mathrm{PD}$-treated group (two-way ANOVA is followed by the Bonferroni's post hoc test).

Abbreviations: HALO, haloperidol; RISP, risperidone.

a statistically significant antianxiety-like activity in the Vogel conflict drinking paradigm. In contrast, a specific anxiolytic-like effect was observed after repeated administration of SB-742457 with risperidone in the EPM test, while in the Vogel conflict drinking test the $5-\mathrm{HT}_{6} \mathrm{R}$ antagonist did not affect the activity of the APD, either after single or multiple doses. The tested compounds, administered both alone and in combinations, differently modulated the levels of BDNF protein and the expression of $B D N F$ gene in the hippocampus and prefrontal cortex of rats, but these changes were not correlated with the effects observed in the behavioral studies (summary in Table 5).

Considering the depressive-like effect of acutely administered haloperidol in FST, it should be noted that a decline in the locomotor activity of animals was observed simultaneously during OFT. This sedative influence of the APD may, at least in part, account for its prodepressive-like activity in FST, although the effect was not statistically significant. The unfavorable impact of haloperidol on the animals' behavior in FST was also seen after its repeated administration; however, the effect was not accompanied by a reduction in motility as observed in OFT, which indicates the specificity of the prodepressive action of haloperidol. These findings agree with the results reported in scientific literature and confirm the prodepressive potential of haloperidol. Such effect associated with haloperidol was found after its single administration in FST in rats, ${ }^{44}$ mice, ${ }^{45}$ and gerbils ${ }^{46}$ as well as in TST in mice. ${ }^{47}$ Similarly, after repeated administration, the unfavorable effect of haloperidol on mouse behavior was observed in FST and $\mathrm{TST}^{48}$ and depressive behaviors were also induced in the model of chronic unpredictable mild stress in rats. ${ }^{49}$ For the reliability of 
Table 4 Effects of 2I-Day Administration of Haloperidol, Risperidone, WAY-181187, and SB-742457, Alone and in Combinations, on the Total Exploration of Rats in the EPM Test

\begin{tabular}{|l|c|c|}
\hline Treatment (mg/kg) & Total Entries & Total Distance (cm) \\
\hline Vehicle & $34.4 \pm 2.5$ & $4647.0 \pm 141.9$ \\
HALO (0.5) & $29.3 \pm 3.9$ & $3934.6 \pm 255.2^{\mathrm{a}}$ \\
WAY-I8II87 (3.0) & $36.9 \pm 3.0$ & $4721.9 \pm 135.5$ \\
HALO (0.5) + WAY (3.0) & $29.1 \pm 3.6$ & $4324.1 \pm 152.9$ \\
Vehicle & $33.7 \pm 3.0$ & $4536.6 \pm 172.0$ \\
RISP (0.2) & $38.1 \pm 4.9$ & $4470.0 \pm 192.0$ \\
WAY-I8II87 (3.0) & $36.9 \pm 3.0$ & $4721.9 \pm 135.5$ \\
RISP (0.2) + WAY (3.0) & $31.8 \pm 2.6$ & $4302.2 \pm 132.1$ \\
Vehicle & $34.4 \pm 2.5$ & $4647.0 \pm 141.9$ \\
HALO (0.5) & $29.3 \pm 3.9$ & $3934.6 \pm 255.2^{\mathrm{a}}$ \\
SB-742457 (3.0) & $33.7 \pm 3.2$ & $4450.8 \pm 180.6$ \\
HALO (0.5) + SB (3.0) & $35.6 \pm 3.9$ & $4570.2 \pm 195.2$ \\
Vehicle & $33.2 \pm 3.1$ & $4308.9 \pm 177.9$ \\
RISP (0.2) & $38.1 \pm 4.9$ & $4470.0 \pm 192.0$ \\
SB-742457 (3.0) & $33.7 \pm 3.2$ & $4450.8 \pm 180.6$ \\
RISP (0.2) + SB (3.0) & $37.3 \pm 3.3$ & $4232.6 \pm 417.7$ \\
\hline
\end{tabular}

Notes: Data are presented as the mean \pm SEM; ${ }^{a}{ }^{2}<0.05$ vs respective contro group (two-way ANOVA is followed by the Bonferroni's post hoc test).

Abbreviations: HALO, haloperidol; RISP, risperidone; WAY, WAY-18I I87; SB, SB742457.

cited data, it should be mentioned that there exist studies showing the lack of influence of acute-administered haloperidol on the behaviors observed in FST in mice and rats. $^{50,51}$

In line with the aim of the study, further experiments were carried out to determine whether the addition of a selective $5-\mathrm{HT}_{6} \mathrm{R}$ agonist or antagonist to haloperidol would change its adverse effect in FST. A single administration of WAY-181187 with haloperidol alleviated its prodepressive activity and significantly reduced the immobility time and increased the climbing time in FST, compared to APD-alone administration. The antidepressant-like effect of the combined administration observed in FST was accompanied by a significant decrease in the general locomotor activity of rats measured in OFT, which suggests that despite the high sedative potential of such combination, its antidepressant-like effect is specific. Sedation is clinically viewed as an adverse effect associated with the pharmacotherapy of psychiatric disorders. Thus, it should be taken into account that despite its antidepressant-like potential, such a combination may lead to the occurrence of an undesirable sedative effect. Contrary to a selective $5-\mathrm{HT}_{6} \mathrm{R}$ agonist, SB-742457, when administered acutely, did not affect the prodepressive effect of once-administered haloperidol, and no changes in locomotor activity were observed after its administration in combination with haloperidol.

In the experiments performed after repeated administration of haloperidol and WAY-181187, an entire antidepressant-like effect on both parameters measured in FST could be seen. In our study, combined administration of the $5-\mathrm{HT}_{6} \mathrm{R}$ agonist and haloperidol evoked a weak, but still significant, increase in the motility of rats in OFT. This observation can indicate the lack of specificity of the antidepressant-like effect observed in FST. However, comparing the numerical values of parameters related to the motor-stimulating effect of the haloperidol/WAY-181187 or haloperidol/SB-742457 combination, it can be concluded that the effects are very similar, while in the case of repeated combined administration of haloperidol and SB-742457 no antidepressant-like activity in FST was observed and the increase in climbing time was not as pronounced as noted with the combined administration of haloperidol and WAY-181187.

In the present study, both acute and repeated administration of haloperidol caused anxiogenic effects in EPM; however, a significant effect was noted only after single administration when the decrease in the exploratory activity of rats was greater than after chronic injection. Hence, it may be concluded that the anxiogenic effect of haloperidol measured in EPM was the result of its sedative action. In the Vogel conflict drinking test, haloperidol did not significantly change the measured parameters after both single and repeated administration. However, depending on the dosing regimen used, the trend of action was observed to differ. A single dose of haloperidol caused an insignificant increase in the number of licks and the number of shocks accepted by the animals, whereas after repeated administration a slight decrease in the measured parameters was noted, which rather suggests a certain anxiogenic potential of the APD. Literature data from preclinical studies on haloperidol are ambiguous, and the researchers have reported that both single and repeated administration of haloperidol had no effect in EPM, ${ }^{52}$ or that no anxiolytic activity was observed in this test after a single-dose administration. ${ }^{45}$ Both the above-cited studies demonstrated that haloperidol caused a significant decrease in the locomotor activity of mice. On the other hand, the APD administered repeatedly caused anxiogenic-like activity in the EPM test and OFT in rats. ${ }^{53}$ In the experiments conducted by Siemiątkowski et al, acute administration of haloperidol did not result in anticonflict activity in the Vogel test or showed an anxiogenic-like 


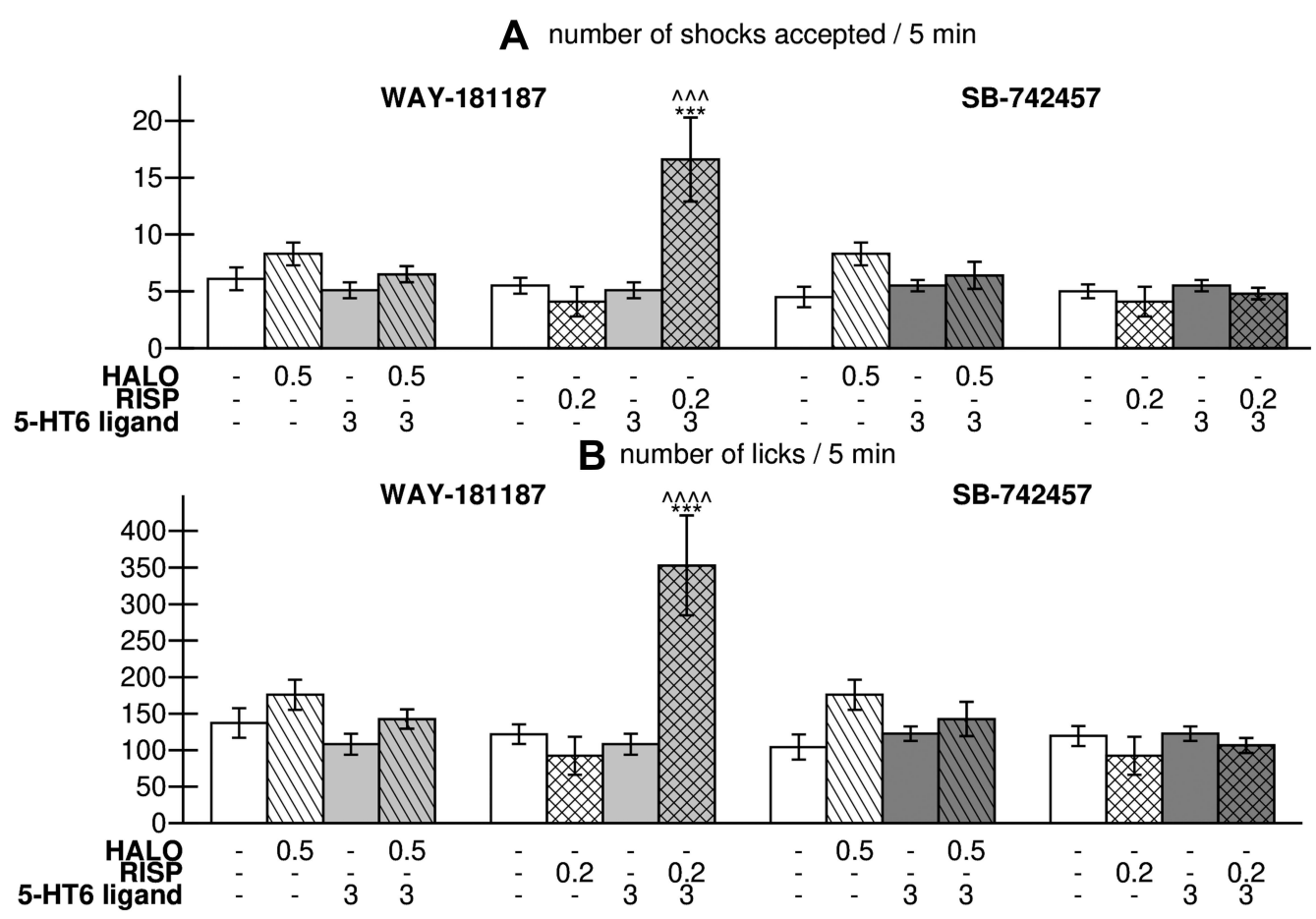

Figure 5 Effects of acute administration of haloperidol, risperidone, WAY-18II87, and SB-742457, alone and in combinations, on number of shocks accepted (A) and number of licks (B) in Vogel conflict drinking test in rats.

Notes: Data are presented as the mean \pm SEM; ${ }^{* * *} p<0.00$ I vs control group, ${ }^{\wedge \wedge \wedge} p<0.05, \wedge \wedge \wedge \wedge p<0.000$ I vs respective APD-treated group (two-way ANOVA is followed by the Bonferroni's post hoc test).

Abbreviations: HALO, haloperidol; RISP, risperidone.
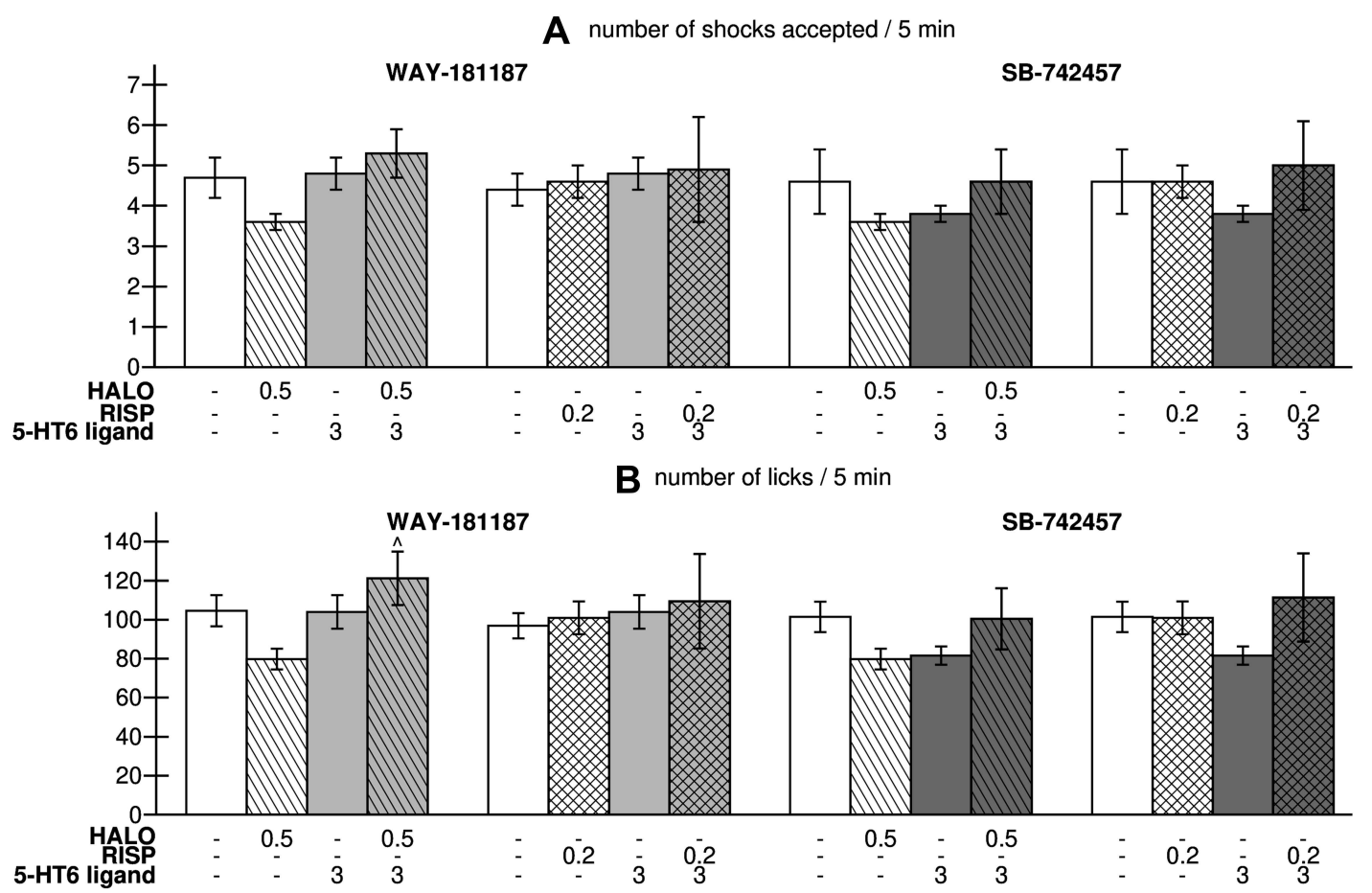

Figure 6 Effects of 21 -day administration of haloperidol, risperidone, WAY-181 I87, and SB-742457, alone and in combinations, on number of shocks acceped (A) and number of licks (B) in Vogel conflict drinking test in rats.

Notes: Data are presented as the mean \pm SEM; ${ }^{\wedge} \mathrm{p}<0.05$ vs respective APD-treated group (two-way ANOVA is followed by the Bonferroni's post hoc test). Abbreviations: HALO, haloperidol; RISP, risperidone. 


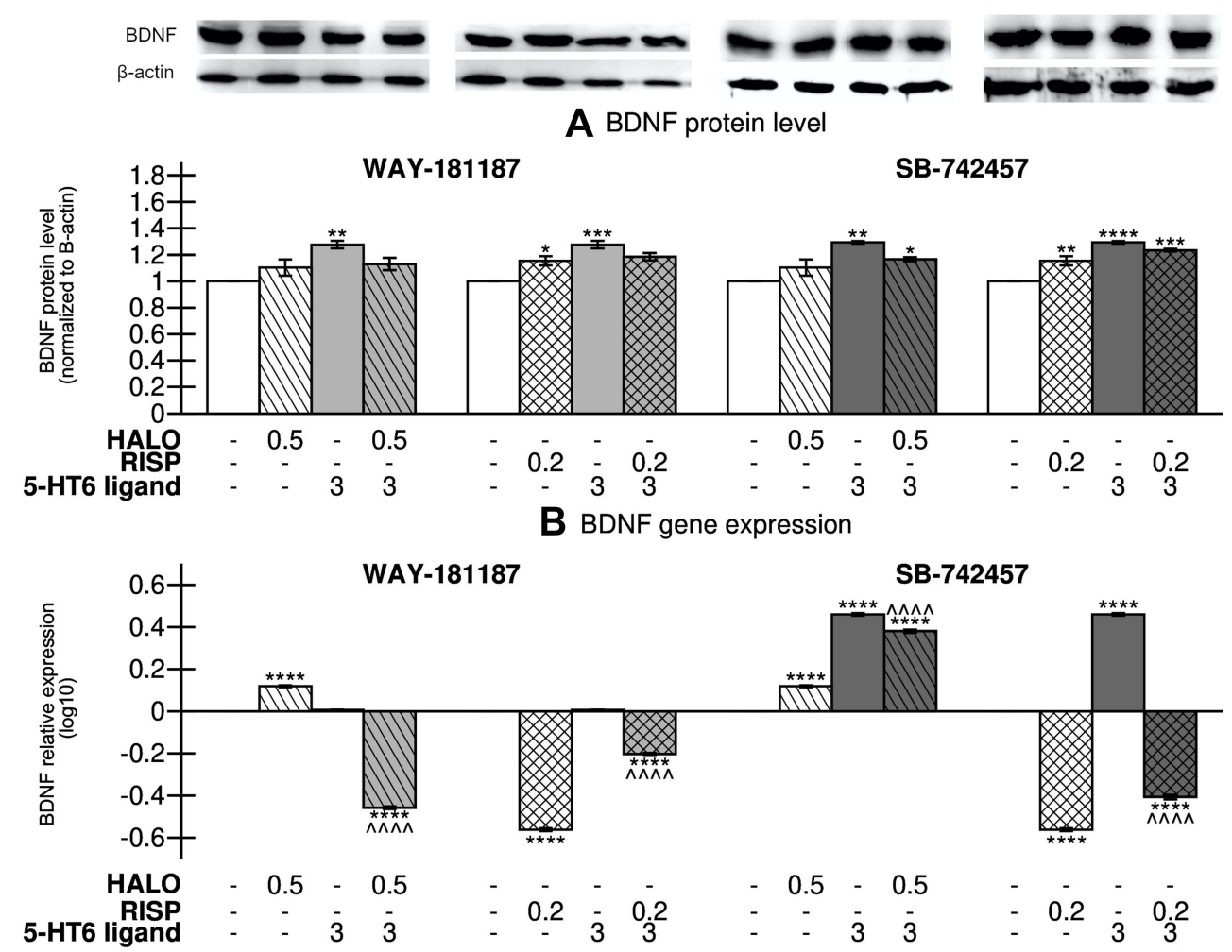

Figure 7 Effects of 21 -day administration of haloperidol, risperidone, WAY-18II87, and SB-742457, alone and in combinations, on the relative level of BDNF protein (A) and relative normalized expression of $B D N F$ gene $(\mathbf{B})$ in the hippocampus of rats.

Notes: Data are presented as the mean \pm SEM; ${ }^{*} p<0.05,{ }^{*} p<0.01, * * * p<0.001$, $* * * * p<0.0001$ vs respective control group, $\wedge \wedge \wedge \wedge<<0.000$ I vs respective APD-treated group (two-way ANOVA is followed by the Bonferroni's post hoc test).

Abbreviations: HALO, haloperidol; RISP, risperidone.

effect in $\mathrm{OFT}^{54}$ and the ultrasonic vocalization test ${ }^{55}$ in rats. The findings of our study correspond well with the piece of data, indicating the potential proanxiety effect of haloperidol.

The addition of WAY-181187 to haloperidol, after a single administration, did not change the adverse effect of this APD on both anxiety behavior and exploratory activity of rats in EPM. On the other hand, repeated combined injections of both substances resulted in a clear, although insignificant, mitigation of the anxiogenic effect of haloperidol. It seems that the beneficial effect observed with the addition of WAY-181187 to haloperidol after repeated administration may rather be related to the reversal of the APD's sedative action. Similar effects of combined administration were recorded in the Vogel test. The acute combined administration of APD and WAY181187 did not change the measured parameters, whereas chronic combined administration led to a significant increase in the number of licks and an insignificant increase in the number of accepted shocks as compared to the haloperidol-alone administration.
The addition of the $5-\mathrm{HT}_{6} \mathrm{R}$ antagonist to haloperidol attenuated its anxiogenic effect in EPM after both single and chronic administration. Although the anxiogenic action was maintained after acute combined treatment, a several-fold increase in all the measured parameters was noted in comparison to the group receiving haloperidol alone, along with a reduction in the sedative effect. Repeated combined administration of haloperidol and SB-742457 was followed by a significant anxiolytic activity manifested by an increase in all the measured parameters while no influence on exploratory activity was noted in EPM. In the Vogel test, no effect of acute or chronic combined administration of haloperidol and SB742457 was observed. These results indicate that haloperidol in combination with the $5-\mathrm{HT}_{6} \mathrm{R}$ antagonist can produce a more pronounced task-specific anxiolytic-like action, especially after repeated administration, since their effects were observed only in the case of "unconditional" anxiety-like paradigm (EPM).

The obtained results suggest that both single and chronic addition of the $5-\mathrm{HT}_{6} \mathrm{R}$ agonist to haloperidol allowed for the 

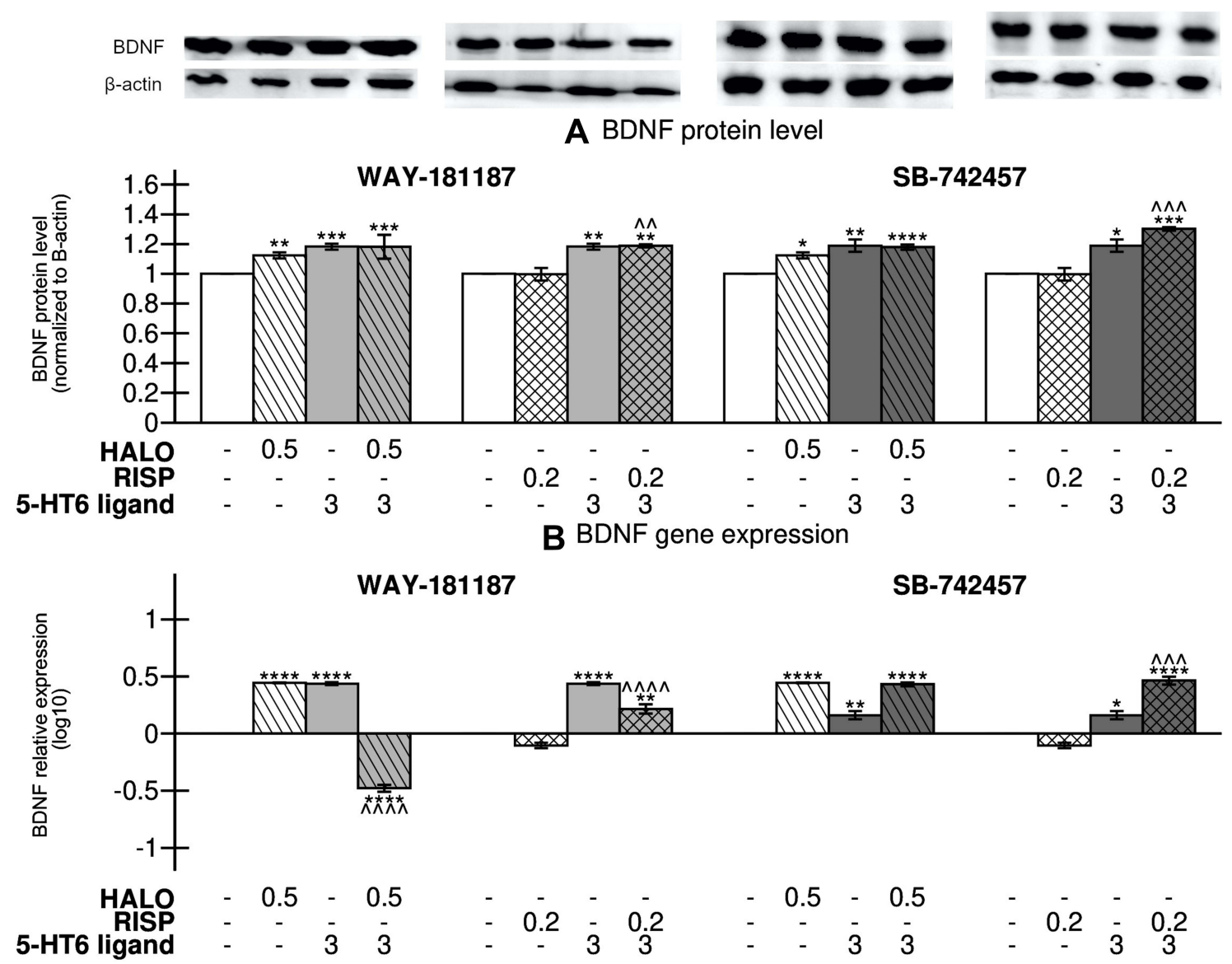

Figure 8 Effects of 2I-day administration of haloperidol, risperidone, WAY-I8II87, and SB-742457, alone and in combinations, on the relative level of BDNF protein (A) and relative normalized expression of $B D N F$ gene $(\mathbf{B})$ in the prefrontal cortex of rats.

Notes: Data are presented as the mean \pm SEM; ${ }^{*} p<0.05, *^{*} p<0.0$ I, $* * * p<0.00$ I, ${ }^{*} * * * p<0.000$ I vs respective control group, ${ }^{\wedge \wedge} p<0.0$ I, ${ }^{\wedge \wedge \wedge} p<0.00$ I, $\wedge \wedge \wedge \wedge p<0.000$ I vs respective APD-treated group (two-way ANOVA is followed by the Bonferroni's post hoc test).

Abbreviations: HALO, haloperidol; RISP, risperidone.

elimination of its prodepressive and anxiogenic effects and even resulted in beneficial antidepressant- and anxiolytic-like activities. In contrast, the addition of the $5-\mathrm{HT}_{6} \mathrm{R}$ antagonist did not provide full benefits in terms of improvement of adverse mood effects induced by haloperidol. It seems that the desirable, anxiolytic-like effects observed with the addition of $5-\mathrm{HT}_{6} \mathrm{R}$ ligands to haloperidol may be task-specific. The anxiolytic-like effect of WAY-181187 combined with this APD was visible in the anxiety "conditional" model (Vogel conflict drinking test), whereas SB-742457 showed such activity in combination with the APD in the "unconditional" assay (EPM test). It should be noted that the differences observed in the behavioral effects produced by the agonist and antagonist of $5-\mathrm{HT}_{6} \mathrm{R}$ may also depend on the action of the single dose of these compounds. WAY-181187 administered at an acute dose of $3 \mathrm{mg} / \mathrm{kg}$ produced an antidepressant-like effect, whereas the same dose of SB-72457 was inactive. However, after repeated administration, the dose of $3 \mathrm{mg} / \mathrm{kg}$ of both substances was found to be ineffective in FST. Similarly, in anxiety models, both WAY-181187 and SB-742457 used at a dose of $3 \mathrm{mg} / \mathrm{kg}$ did not show significant anxiolytic-like properties in acute and chronic experiments. Based on the numerical values, the effect of SB-742457 seemed to be more pronounced than that of WAY-181187, especially in EPM after a single dose; however, it may have been due to an increase in the exploratory activity. In the clinic prodepressive effect of haloperidol was observed. $^{56-58}$ Because haloperidol has no affinity for 5- $\mathrm{HT}_{6} \mathrm{R}$, then an addition of an agent with such an ability may cause potential antidepressant activity of haloperidol. The lack of literature data on the effect of combined administration of haloperidol with $5-\mathrm{HT}_{6} \mathrm{R}$ ligands does not allow drawing more precise conclusions.

In the present study, risperidone administered both once and repeatedly did not affect the behavior of animals in FST. These results differ from those of the preclinical studies 


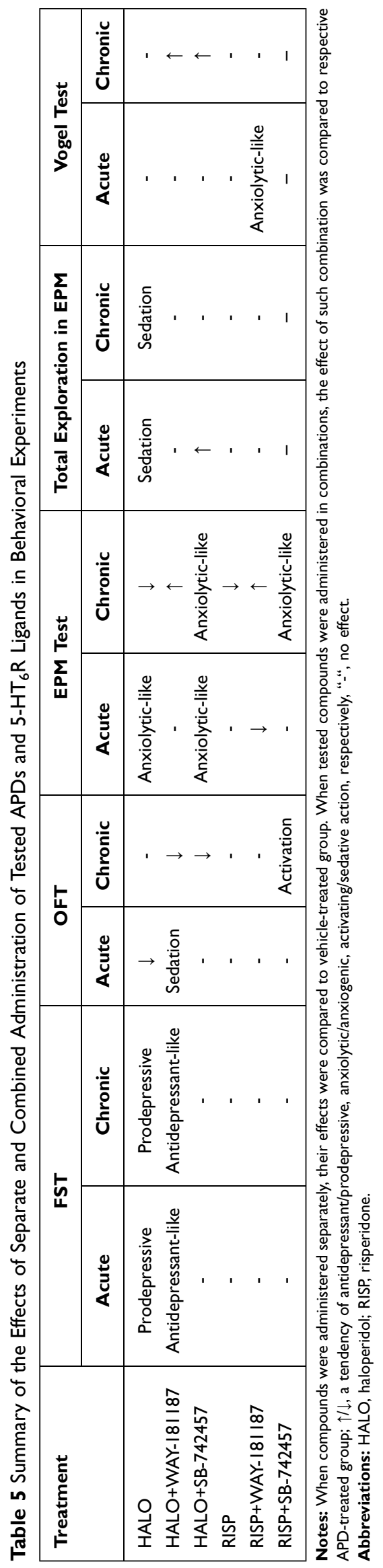

reported in the literature, in which the APD administered once at doses of $0.25-0.3 \mathrm{mg} / \mathrm{kg}$ demonstrated potential antidepressant activity ${ }^{59}$ and reversed the prodepressant effect caused by repeated administration of ketamine in rat FST. ${ }^{60}$ The reason for the lack of antidepressant activity of risperidone in the present study may be the use of too low dose of risperidone (ie, $0.2 \mathrm{mg} / \mathrm{kg}$ ). In addition to the direct antidepressant-like effect of risperidone observed in animal tests, the results of preclinical studies also suggested the synergistic effect of risperidone and antidepressants. Risperidone used in inactive doses $(0.05-0.1 \mathrm{mg} / \mathrm{kg})$ induced and/or enhanced the antidepressant-like activity of selected antidepressants in mice and rats in FST. ${ }^{61-65}$ For depressive symptoms, a $5-\mathrm{HT}_{6} \mathrm{R}$ agonist or antagonist could be considered as an add-on treatment to be used in combination with APD, in this case risperidone. However, the addition of WAY-181187 or SB-742457 to risperidone in both single and multiple administrations did not influence the effect of APD administered alone in FST.

Single administration of risperidone did not lead to an anxiolytic-like effect in EPM. In contrast, repeated administration of risperidone resulted in an anxiogenic-like tendency at the applied dose, which was expressed by a reduction in all the EPM parameters measured. The observed effect, although not significant, can be considered specific as it was not accompanied by any changes in the exploratory activity of animals. Similarly, acute and chronic administration of risperidone had no effect in the Vogel conflict drinking test. These results are inconsistent with the literature data, which show that risperidone administered once caused an anxiolytic-like effect in EPM and Vogel conflict tests in rats ${ }^{66}$ and enhanced the anxiolyticlike effect of antidepressants in rats in EPM. ${ }^{62,67}$ The discrepancy between the results of our research and those from the literature may be related to the differences in the doses of APD, rat strains and experimental conditions.

Addition of WAY-181187 to risperidone, after both acute and chronic administration, produced no anxiolyticlike effect in the EPM test. This combination also showed no effect on the exploratory activity measured in EPM. A positive effect was observed only in the Vogel test, in which single combined administration of WAY-181187 and risperidone resulted in a statistically significant increase in the number of licks and the number of shocks accepted by the animals. At the same time, this combination did not significantly change the pain threshold and the amount of water taken by rats, which suggests the specificity of the observed anxiolytic activity. However, the 
anxiolytic-like effect was not maintained after repeated combined administration.

In the EPM test, the addition of SB-742457 to risperidone, after acute administration, did not influence the effects of the APD administered alone in terms of anxiolytic-like effect and motor activity. In contrast, a specific anxiolytic-like effect was observed after repeated administration of both substances. Risperidone and SB-742457 significantly extended the time and increased the percentage of time spent in the open arms and the percentage of entries into these arms. Simultaneous administration of both substances was not accompanied by any changes in the motor activity of animals in EPM. In the Vogel test, the addition of $5-\mathrm{HT}_{6} \mathrm{R}$ antagonist to risperidone, either in single or multiple doses, did not affect the activity of the APD administered alone. It is worth noting that the addition of WAY-181187 to risperidone produced greater benefits in the anxiety "conditional" model, while the addition of SB-742457 produced greater benefits in the test based on unconditional anxiety reaction.

The combination of SB-742457 and risperidone was tested in healthy volunteers when a $5-\mathrm{HT}_{6} \mathrm{R}$ antagonist was under development as a possible add-on treatment with an atypical APD for the cognitive symptoms in Alzheimer's disease and schizophrenia. SB-742457 given at a dose of $50 \mathrm{mg}$ for 8 days and risperidone $2 \mathrm{mg}$ administered once did not produce any clinically relevant pharmacokinetic interaction. ${ }^{68}$ Moreover, such combination did not significantly affect the functions of CNS compared to risperidone administered alone which decreased the behavioral and cognitive performance, increased the theta band power of the electroencephalogram (EEG) spectra, decreased saccadic peak velocity, and increased prolactin concentrations. ${ }^{68-71}$ The only significant interaction observed by LiemMoolenaar et al was an increase in the EEG alpha and beta bands, which suggest mild arousal by SB-742457 especially in the presence of risperidone. ${ }^{68}$ This finding could be considered as an indication of the modulation of dopaminergic hypofunctionality by $5-\mathrm{HT}_{6} \mathrm{R}$ antagonism.

The involvement of BDNF in the development of the CNS, the activity of dopaminergic neurons, synapses, and the neurogenesis process suggest its role in the etiology of schizophrenia. ${ }^{72}$ The results from both clinical and preclinical studies on the effects of APDs on BDNF are not conclusive yet and require further clarification. ${ }^{35}$ The postmortem observations of BDNF concentration in the prefrontal cortex of patients with schizophrenia were contrary and showed an increase and a decrease in the level of
BDNF protein, while most of the studies revealed a decrease in the levels of this neurotrophin in peripheral blood serum of people diagnosed with schizophrenia. ${ }^{72}$ BDNF and its signaling partners are also integral to both the pathophysiology of depression/anxiety and the effects (both antidepressant and anxiolytic) of antidepressant drugs. Decreased BDNF-TrkB signaling in the prefrontal cortex, CA3 region, and dentate gyrus of the hippocampus as well as increased signaling in the ventral tegmental area-nucleus accumbens pathway plays a role in the pathophysiology of diseases. ${ }^{73-75}$ Furthermore, reports have suggested the antidepressant-like effects for BDNF in the animal models of depression. ${ }^{76,77}$ Likewise, mechanistic studies in adult animals have demonstrated a link between anxiety and BDNF and proved that mutant rodents with reduced BDNF signaling displayed increased anxiety behaviors. ${ }^{78,79}$ BDNF is closely linked with the serotonergic system of the brain, and along with serotonin it acts as the main factor in the mechanisms of neurogenesis and neuroplasticity. On the one hand, BDNF stimulates the growth of serotonin neurons and affects the expression of key genes of the serotonergic system, while on the other hand, serotonin is implicated in the regulation of BDNF, and for example, was shown to increase the $B D N F$ gene expression and BDNF protein levels in embryonic raphe cell cultures. ${ }^{80}$

In the light of these considerations, we decided to investigate the involvement of hippocampal and cortical BDNF in the behavioral effects of the tested treatment. In the present study, haloperidol administered alone increased the level of BDNF protein and $B D N F$ gene expression in both the studied structures, although its effect was more pronounced in the prefrontal cortex, while risperidone administered alone increased the protein level of BDNF and suppressed its gene expression in the hippocampus with no effect on these parameters in the prefrontal cortex. Both $5-\mathrm{HT}_{6} \mathrm{R}$ ligands did not influence the haloperidolinduced effects on BDNF level in the hippocampus and prefrontal cortex, whereas their influence on $B D N F$ gene expression significantly differed; WAY-181187 decreased the gene expression in both structures, while SB-742457 increased the expression in the hippocampus but not in the prefrontal cortex. In the case of combined administration with risperidone, the action of $5-\mathrm{HT}_{6} \mathrm{R}$ ligands was similar; they elevated the level of BDNF protein in the prefrontal cortex without producing any influence on this parameter in the hippocampus and alleviated the 
repression of the $B D N F$ gene induced by risperidone in both brain structures.

These biochemical data differ to some extent from the observed behavioral outcomes; hence, it seems unlikely that the behavioral antidepressant- and/or anxiolytic-like activities noted with the combined administration of $5-\mathrm{HT}_{6} \mathrm{R}$ ligands with haloperidol or risperidone develop solely as a consequence of changes in BDNF signaling. The other neurotrophins, such as nerve growth factor or neurotrophin-3 (NT-3), were also shown to play a role in the pathophysiology and treatment of psychiatric disorders. ${ }^{77}$ For example, Agostinho et al demonstrated that treatment with fluoxetine (selective serotonin reuptake inhibitor) and olanzapine (APD) alone and in combination did not alter the levels of BDNF protein in the prefrontal cortex, hippocampus and amygdala of rats, but administration of both drugs increased the levels of NT-3 protein in all these brain structures. The authors postulated that NT-3 may be involved in the therapeutic action of olanzapine/fluoxetine combination. ${ }^{81}$ A similar situation may arise in the case of the combined administration of $5-\mathrm{HT}_{6} \mathrm{R}$ ligands and APDs. Furthermore, it is commonly accepted that abnormalities in the central serotonergic, noradrenergic, and dopaminergic neurotransmission play a significant role in the pathomechanism of mood disorders. Neurochemical research demonstrated that haloperidol did not significantly change the level of monoamines whereas risperidone did not produce appreciable changes in the level of serotonin in the prefrontal cortex, ${ }^{82}$ although, in the other study, it increased the levels of serotonin, dopamine, and norepinephrine in the medial prefrontal cortex of rats. ${ }^{83,84}$ It has been established that the antidepressant-like activity of $5-\mathrm{HT}_{6} \mathrm{R}$ ligands observed in FST depends on the enhancement of central noradrenergic, dopaminergic, ${ }^{85,86}$ and GABA/glutamatergic neurotransmissions, ${ }^{22}$ while their anxiolytic-like activity is rather due to a functional interaction between $5-\mathrm{HT}_{6} \mathrm{R}$ and the GABAergic system. ${ }^{22,23}$ Since there are no data on the effects of the combined administration of the tested $5-\mathrm{HT}_{6} \mathrm{R}$ ligands with haloperidol or risperidone on the levels of catecholamines and neurotrophins or interaction with the GABA/glutamatergic system, further discussion of these mechanisms would remain speculative.

This study has few limitations. First of all, the present research is basic and the tests used are screening, which aimed to preliminarily assess whether the combined administration of selective 5- $\mathrm{HT}_{6} \mathrm{R}$ agonist/antagonist with chosen neuroleptics would improve their effectiveness in the treatment of depressive and anxiety symptoms. Second, the antidepressant- and/or anxiolytic-like effects observed in FST and EPM test, respectively, should be confirmed in translational models of depression and/or anxiety in which the locomotor activity does not affect the interpretation of results. Third, it is not clear if the obtained results are universal and may be extrapolated to other APDs, especially those with a higher affinity to $5-\mathrm{HT}_{6} \mathrm{R}$ (like clozapine or olanzapine). Fourth, no correlation was found between the effects of behavioral studies and BDNF level and/or BDNF gene expression. Thus, further research should be warranted to analyze the impact of the tested compounds and their combination on other neurotrophins implicated in the pathomechanism of mood disorders. Although the mechanism underlying the observed behavioral effects has not been fully elucidated, it should be emphasized that the influence of repeated administration (21 days) of selective $5-\mathrm{HT}_{6} \mathrm{R}$ agonist and antagonist on the level of BDNF protein and expression of $B D N F$ gene has been demonstrated for the first time.

In the present study, only administration of the $5-\mathrm{HT}_{6} \mathrm{R}$ agonist combined with haloperidol produced a significant antidepressant-like activity, while administration of both $5-\mathrm{HT}_{6} \mathrm{R}$ agonist and antagonist in combination with haloperidol and/or risperidone produced anxiolytic-like effect. Their anxiolytic activity varied depending on the models used. The $5-\mathrm{HT}_{6} \mathrm{R}$ agonist was active in the "conditional" model of anxiety that may be used as a predictor for identifying effective drugs or their combination for managing generalized anxiety disorders and acute anxiety states. ${ }^{31}$ On the other hand, the $5-\mathrm{HT}_{6} \mathrm{R}$ antagonist was active in the "unconditional" assay, a procedure based on the rodents' natural aversion to heights and open spaces, and such model is considered to reflect phobic anxiety states. $^{29}$ The observed anxiolytic-like activity was more complete and expressive when an antagonist was administered together with risperidone. Such action of risperidone showed a positive effect on the level of BDNF and its gene expression in the prefrontal cortex and a weaker effect in the hippocampus, and these changes, at least in part, may be responsible for its anxiolytic effect. Although the same biochemical effect was noted for risperidone with WAY-181187, no positive behavioral action was observed.

Anxiety symptoms are very common in patients with schizophrenia. The use of first-generation APDs alone is not recommended for the treatment of generalized anxiety and obsessive-compulsive disorders as well as for alleviating social phobia and panic attacks, ie, anxiety disorders, which most often accompany schizophrenia. ${ }^{10,11}$ In such cases, addon treatment with a $5-\mathrm{HT}_{6} \mathrm{R}$ agonist could be recommended. The clinical efficacy of risperidone has been demonstrated in 
the case of anxiety symptoms associated with schizophrenia, ${ }^{87}$ bipolar disorder, ${ }^{88}$ and post-traumatic stress disorder, ${ }^{89}$ but some other data show that the therapeutic action of this APD is not sufficient enough to relieve anxiety and depressive symptoms. ${ }^{90}$ Moreover, in treatment with risperidone, the addition of a $5-\mathrm{HT}_{6} \mathrm{R}$ antagonist would be more efficacious since these substances do not evoke pharmacokinetic interactions. $^{68}$

\section{Conclusions}

In conclusion, it should be noted that the greatest benefits were obtained after the combined administration of WAY181187 and haloperidol. The $5-\mathrm{HT}_{6} \mathrm{R}$ agonist not only contributed to the suppression of the depressive-like effects of APDs but also led to the disclosure of antidepressant-like effects in FST. Moreover, WAY-181187 weakened the anxiogenic properties of haloperidol. In the case of risperidone, the desired effect of the combined administration with both an agonist and an antagonist was noted only with regard to the anxiolytic-like activity. It seems that the anxiolytic-like effects observed with the addition of $5-\mathrm{HT}_{6} \mathrm{R}$ ligands to haloperidol and risperidone are taskspecific. Based on the behavioral and biochemical findings obtained, it is difficult to say whether the addition of a selective $5-\mathrm{HT}_{6} \mathrm{R}$ agonist or antagonist will serve better in the treatment with APD. The effect of these ligands may depend on the clinical condition of the patient and the profile of APD used; therefore, further research is needed.

\section{Acknowledgment}

The study was financially supported by National Science Center (Poland) [Grant No. UMO-2015/19/B/NZ7/00227]

\section{Disclosure}

The authors report no conflicts of interest in this work.

\section{References}

1. Hudepohl NS, Nasrallah HA. Antipsychotic Drugs. Vol. 106. 1sted. Elsevier B.V; 2012. doi:10.1016/B978-0-444-52002-9.00039-5

2. Lally J, MacCabe JH. Antipsychotic medication in schizophrenia: a review. Br Med Bull. 2015;114(1):169-179. doi:10.1093/bmb/ldv017

3. Brooke NS, Wiersgalla M, Salzman C. Atypical uses of atypical antipsychotics. Harv Rev Psychiatry. 2005;13(6):317-339. doi:10. 1080/10673220500433148

4. Carson WH, Kitagawa H. Drug development for anxiety disorders: new roles for atypical antipsychotics. Psychopharmacol Bull. 2004;38 (1):38-45.

5. Wright BM, Eiland EH, Lorenz R. Augmentation with atypical antipsychotics for depression: a review of evidence-based support from the medical literature. Pharmacother J Hum Pharmacol Drug Ther. 2013;33(3):344-359. doi:10.1002/phar.12047
6. Stein DJ, Westenberg HGM, Liebowitz MR. Social anxiety disorder and generalized anxiety disorder: serotonergic and dopaminergic neurocircuitry. J Clin Psychiatry. 2002;63(Suppl 6):12-19.

7. Hollander E, Rossi NB, Sood E, Pallanti S. Risperidone augmentation in treatment-resistant obsessive-compulsive disorder: a doubleblind, placebo-controlled study. Int J Neuropsychopharmacol. 2003;6 (4):S1461145703003730. doi:10.1017/S1461145703003730

8. Conley RR, Ascher-Svanum H, Zhu B, Faries DE, Kinon BJ. The burden of depressive symptoms in the long-term treatment of patients with schizophrenia. Schizophr Res. 2007;90(1-3):186-197. doi:10. 1016/j.schres.2006.09.027

9. Braga RJ, Reynolds GP, Siris SG. Anxiety comorbidity in schizophrenia. Psychiatry Res. 2013;210(1):1-7. doi:10.1016/j. psychres.2013.07.030

10. Temmingh H, Stein DJ. Anxiety in patients with schizophrenia: epidemiology and management. CNS Drugs. 2015;29(10):819-832. doi: $10.1007 / \mathrm{s} 40263-015-0282-7$

11. Pignon B, Tezenas Du Montcel C, Carton L, Pelissolo A. The place of antipsychotics in the therapy of anxiety disorders and obsessive-compulsive disorders. Curr Psychiatry Rep. 2017;19(12). doi:10.1007/s11920-017-0847-x

12. Monsma FJ, Shen Y, Ward RP, Hamblin MW, Sibley DR. Cloning and expression of a novel serotonin receptor with high affinity for tricyclic psychotropic drugs. Mol Pharmacol. 1993;43(3):320-327.

13. Ruat M, Traiffort E, Arrang JM, et al. A novel rat serotonin (5-HT6) receptor: molecular cloning, localization and stimulation of cAMP accumulation. Biochem Biophys Res Commun. 1993;193(1):268-276. doi:10.1006/bbrc.1993.1619

14. Zajdel P, Marciniec K, Satała G, et al. N1-azinylsulfonyl-1H-indoles: 5-HT6 receptor antagonists with procognitive and antidepressant-like properties. ACS Med Chem Lett. 2016;7(6):618-622. doi:10.1021/ acsmedchemlett.6b00056

15. Wesołowska A, Nikiforuk A. Effects of the brain-penetrant and selective 5-HT6receptor antagonist SB-399885 in animal models of anxiety and depression. Neuropharmacology. 2007;52(5):1274-1283. doi:10.1016/j.neuropharm.2007.01.007

16. Wesołowska A, Nikiforuk A, Stachowicz K. Anxiolytic-like and antidepressant-like effects produced by the selective 5-HT6 receptor antagonist SB-258585 after intrahippocampal administration to rats. Behav Pharmacol. 2007;18(5-6):439-446. doi:10.1097/FBP.0b013e $3282 \mathrm{~d} 28 \mathrm{f} 9 \mathrm{c}$

17. Nikiforuk A, Kos T, Wesołowska A. The 5-HT6 receptor agonist EMD 386088 produces antidepressant and anxiolytic effects in rats after intrahippocampal administration. Psychopharmacology. 2011;217(3):411-418. doi:10.1007/s00213-011-2297-1

18. Carr GV, Schechter LE, Lucki I. Antidepressant and anxiolytic effects of selective 5-HT6 receptor agonists in rats. Psychopharmacology. 2011;213 (2-3):499-507. doi:10.1007/s00213-010-1798-7

19. Svenningsson P, Tzavara ET, Qi H, et al. Biochemical and behavioral evidence for antidepressant-like effects of 5-HT6 receptor stimulation. $J$ Neurosci. 2007;27(15):4201-4209. doi:10.1523/ JNEUROSCI.3110-06.2007

20. Hamon M, Doucet E, Lefevre K, et al. Antibodies and antisense oligonucleotide for probing the distribution and putative functions of central 5-HT6 receptors. Neuropsychopharmacology. 1999;21(2 Suppl):68S-76S. doi:10.1016/S0893-133X(99)00044-5

21. Otano A, Frechilla D, Cobreros A, et al. Anxiogenic-like effects and reduced stereological counting of immunolabelled 5-hydroxytryptamine6 receptors in rat nucleus accumbens by antisense oligonucleotides. Neuroscience. 1999;92(3):1001-1009. doi:10.1016/ S0306-4522(99)00066-4

22. Schechter LE, Lin Q, Smith DL, et al. Neuropharmacological profile of novel and selective 5-HT6 receptor agonists: WAY-181187 and WAY-208466. Neuropsychopharmacology. 2008;33(6):1323-1335. doi:10.1038/sj.npp.1301503 
23. Wesolowska A. The anxiolytic-like effect of the selective 5-HT6 receptor antagonist SB-399885: the impact of benzodiazepine receptors. Eur J Pharmacol. 2008;580(3):355-360. doi:10.1016/j. ejphar.2007.11.022

24. East SZ, Burnet PWJ, Leslie RA, Roberts JC, Harrison PJ. 5-HT6 receptor binding sites in schizophrenia and following antipsychotic drug administration: autoradiographic studies with [125I]SB-258585. Synapse. 2002;45(3):191-199. doi:10.1002/syn.10097

25. Frederick JA, Meador-Woodruff JH. Effects of clozapine and haloperidol on 5-HT6 receptor mRNA levels in rat brain. Schizophr Res. 1999;38(1):7-12. doi:10.1016/S0920-9964(99)00002-X

26. Nikiforuk A. The procognitive effects of 5-HT6 receptor ligands in animal models of schizophrenia. Rev Neurosci. 2014;25(3):367-382. doi:10.1515/revneuro-2014-0005

27. Khoury R, Grysman N, Gold J, Patel K, Grossberg GT. The role of 5 HT6-receptor antagonists in Alzheimer's disease: an update. Expert Opin Investig Drugs. 2018;27(6):523-533. doi:10.1080/13543784.20 18.1483334

28. Wesołowska A, Jastrzębska-Więsek M. Behavioral pharmacology: potential antidepressant and anxiolytic properties. Int Rev Neurobiol. 2011;96:49-71. doi: 10.1016/B978-0-12-3859020.00003-6

29. Graeff FG, Guimarães FS, De Andrade TGCS, Deakin JFW. Role of 5-HT in stress, anxiety, and depression. Pharmacol Biochem Behav. 1996;54(1):129-141. doi:10.1016/0091-3057(95)02135-3

30. Schlaepfer T, Nemeroff CB. In: Neurobiology of Psychiatric Disorders. Vol. 106. 1st ed. Elsevier; 2012.

31. Millan MJ, Brocco M. The vogel conflict test: procedural aspects, $\gamma$ aminobutyric acid, glutamate and monoamines. Eur J Pharmacol. 2003;463(1-3):67-96. doi:10.1016/S0014-2999(03)01275-5

32. Kusumi I, Boku S, Takahashi Y. Psychopharmacology of atypical antipsychotic drugs: from the receptor binding profile to neuroprotection and neurogenesis. Psychiatry Clin Neurosci. 2015;69(5):24 3-258. doi:10.1111/pcn. 12242

33. Grychowska K, Satała G, Kos T, et al. Novel $1 \mathrm{H}$-pyrrolo[3,2- c] quinoline based 5-HT 6 receptor antagonists with potential application for the treatment of cognitive disorders associated with Alzheimer's disease. ACS Chem Neurosci. 2016;7(7):972-983. doi:10.1021/acschemneuro.6b00090

34. Peng S, Li W, Lv L, Zhang Z, Zhan X. BDNF as a biomarker in diagnosis and evaluation of treatment for schizophrenia and depression. Discov Med. 2018;26(143):127-136.

35. Pandya CD, Kutiyanawalla A, Pillai A. BDNF-TrkB signaling and neuroprotection in schizophrenia. Asian $J$ Psychiatr. 2013;6 (1):22-28. doi:10.1016/j.ajp.2012.08.010

36. Nair A, Jacob S. A simple practice guide for dose conversion between animals and human. J Basic Clin Pharm. 2016;7(2):27. doi:10.4103/0976-0105.177703

37. Upton N, Chuang TT, Hunter AJ, Virley DJ. 5-HT6 receptor antagonists as novel cognitive enhancing agents for Alzheimer's disease. Neurotherapeutics. 2008;5(3):458-469. doi:10.1016/j.nurt.2008.05.008

38. Rychtyk J, Partyka A, Gdula-Argasińska J, et al. 5-HT6 receptor agonist and antagonist improve memory impairments and hippocampal BDNF signaling alterations induced by MK-801. Brain Res. 2019;1722:146375. doi:10.1016/j.brainres.2019.146375

39. Porsolt RD, Anton G, Blavet N, Jalfre M. Behavioural despair in rats: a new model sensitive to antidepressant treatments. Eur J Pharmacol. 1978;47(4):379-391. doi:10.1016/0014-2999(78)90118-8

40. Detke MJ, Rickels M, Lucki I. Active behaviors in the rat forced swimming test differentially produced by serotonergic and noradrenergic antidepressants. Psychopharmacology. 1995;121(1):66-72. doi:10.1007/BF02245592

41. Pellow S, Chopin P, File SE, Briley M. Validation of open: closed arm entries in an elevated plus-maze as a measure of anxiety in the rat. J Neurosci Methods. 1985;14(3):149-167. doi:10.1016/01650270(85) $90031-7$
42. Vogel JR, Beer B, Clody DE. A simple and reliable conflict procedure for testing anti-anxiety agents. Psychopharmacologia. 1971;21 (1):1-7. doi:10.1007/BF00403989

43. Eddy NB, Leimbach D. Synthetic analgesics. II. Dithienylbutenyland dithienylbutylamines. $J$ Pharmacol Exp Ther. 1953;107 (3):385-393

44. Weiner I, Schiller D, Gaisler-Salomon I, Green A, Joel D. A comparison of drug effects in latent inhibition and the forced swim test differentiates between the typical antipsychotic haloperidol, the atypical antipsychotics clozapine and olanzapine, and the antidepressants imipramine and paroxetine. Behav Pharmacol. 2003;14 (3):215-222. doi:10.1097/00008877-200305000-00005

45. Gumuslu E, Mutlu O, Kokturk S, et al. Effects of asenapine and paliperidone on depression, anxiety and analgesy in mice: alterations in brain neurotrophic factors, neurogenesis, and blood enzyme levels. Chin J Physiol. 2018;61(5):280-292. doi:10.4077/CJP.2018.BAH626

46. Wallace-Boone TL, Newton AE, Wright RN, Lodge NJ, McElroy JF. Behavioral and pharmacological validation of the gerbil forced-swim test: effects of neurokinin-1 receptor antagonists. Neuropsychopharmacology. 2008;33(8):1919-1928. doi:10.1038/sj.npp.1301586

47. Cryan JF, Mombereau C, Vassout A. The tail suspension test as a model for assessing antidepressant activity: review of pharmacological and genetic studies in mice. Neurosci Biobehav Rev. 2005;29(45):571-625. doi:10.1016/j.neubiorev.2005.03.009

48. Galani V, Rana D. Dopamine mediated antidepressant effect of Mucuna pruriens seeds in various experimental models of depression. AYU (An Int $Q J$ Res Ayurveda). 2014;35(1):90. doi:10.4103/0974-8520.141949

49. Morais M, Patrício P, Mateus-Pinheiro A, et al. The modulation of adult neuroplasticity is involved in the mood-improving actions of atypical antipsychotics in an animal model of depression. Transl Psychiatry. 2017;7(6):e1146-e1146. doi:10.1038/tp.2017.120

50. Ostadhadi S, Imran Khan M, Norouzi-Javidan A, Dehpour AR. Antidepressant effect of pramipexole in mice forced swimming test: a cross talk between dopamine receptor and NMDA/nitric oxide/ cGMP pathway. Biomed Pharmacother. 2016;81:295-304. doi:10.1016/j.biopha.2016.04.026

51. Joca SRL, Skalisz LL, Beijamini V, Vital MABF, Andreatini R. The antidepressive-like effect of oxcarbazepine: possible role of dopaminergic neurotransmission. Eur Neuropsychopharmacol. 2000;10 (4):223-228. doi:10.1016/S0924-977X(00)00079-1

52. Cole JC, Rodgers RJ. Ethological evaluation of the effects of acute and chronic buspirone treatment in the murine elevated plus-maze test: comparison with haloperidol. Psychopharmacology. 1994;114 (2):288-296. doi:10.1007/BF02244851

53. Karl T, Duffy L, Obrien E, Matsumoto I, Dedova I. Behavioural effects of chronic haloperidol and risperidone treatment in rats. Behav Brain Res. 2006;171(2):286-294. doi:10.1016/j.bbr.2006.04.004

54. Siemiatkowski M, Sienkiewicz-Jarosz H, Czlonkowska AI, Szyndler J, Bidzinski A, Plaznik A. The effects of dopamine D2 receptor ligands on novelty-induced behavior in the rat open field test. Neurosci Res Commun. 2000;27(3):155-163. doi:10.1002/15206769(200011/12)27:3<155::AID-NRC2>3.0.CO;2-R

55. Siemiatkowski M, Maciejak P, Sienkiewicz-Jarosz H, et al. Opposite effects of olanzapine and haloperidol in rat ultrasonic vocalization test. Pol J Pharmacol. 2001;53(6):669-673.

56. Leucht S, Corves C, Arbter D, Engel RR, Li C, Davis JM. Secondgeneration versus first-generation antipsychotic drugs for schizophrenia: a meta-analysis. Lancet. 2009;373(9657):31-41. doi:10.1016/ S0140-6736(08)61764-X

57. Möller HJ. Antidepressive effects of traditional and second generation antipsychotics: a review of the clinical data. Eur Arch Psychiatry Clin Neurosci. 2005;255(2):83-93. doi:10.1007/s00406-005-0580-z

58. Tyler MW, Zaldivar-Diez J, Haggarty SJ. Classics in chemical neuroscience: haloperidol. ACS Chem Neurosci. 2017;8(3):444-453. doi:10.1021/acschemneuro.7b00018 
59. Kołaczkowski M, Mierzejewski P, Bienkowski P, Wesołowska A, Newman-Tancredi A. Antipsychotic, antidepressant, and cognitive-impairment properties of antipsychotics: rat profile and implications for behavioral and psychological symptoms of dementia. Naunyn Schmiedebergs Arch Pharmacol. 2014;387 (6):545-557. doi:10.1007/s00210-014-0966-4

60. Chindo BA, Adzu B, Yahaya TA, Gamaniel KS. Ketamine-enhanced immobility in forced swim test: a possible animal model for the negative symptoms of schizophrenia. Prog Neuro-Psychopharmacology Biol Psychiatry. 2012;38(2):310-316. doi:10.1016/j.pnpbp.2012.04.018

61. Dhir A, Kulkarni SK. Risperidone, an atypical antipsychotic enhances the antidepressant-like effect of venlafaxine or fluoxetine: possible involvement of alpha-2 adrenergic receptors. Neurosci Lett. 2008;445(1):83-88. doi:10.1016/j.neulet.2008.08.074

62. Kaminska K, Rogoz Z. The antidepressant- and anxiolytic-like effects following co-treatment with escitalopram and risperidone in rats. J Physiol Pharmacol. 2016;67(3):471-480.

63. Rogóz Z. Effect of co-treatment with mirtazapine and risperidone in animal models of the positive symptoms of schizophrenia in mice. Pharmacol Reports. 2012;64(6):1567-1572. doi:10.1016/S17341140(12)70955-6

64. Rogóż Z. Effects of co-treatment with mirtazapine and low doses of risperidone on immobility time in the forced swimming test in mice. Pharmacol Rep. 2010;62(6):1191-1196. doi:10.1016/S1734-1140(10) 71165-8

65. Roman A, Kuśmierczyk J, Klimek E, Rogóż Z, Nalepa I. Effects of co-administration of fluoxetine and risperidone on properties of peritoneal and pleural macrophages in rats subjected to the forced swimming test. Pharmacol Reports. 2012;64(6):1368-1380. doi:10.1016/ S1734-1140(12)70934-9

66. Partyka A, Wasik A, Jastrzębska-Więsek M, et al. ADN-1184, a monoaminergic ligand with 5-HT6/7 receptor antagonist action, exhibits activity in animal models of anxiety. Naunyn Schmiedebergs Arch Pharmacol. 2016;389(6):593-602. doi:10.10 07/s00210-016-1229-3

67. Rogóż Z, Skuza G. Anxiolytic-like effects of olanzapine, risperidone and fluoxetine in the elevated plus-maze test in rats. Pharmacol Reports. 2011;63(6):1547-1552. doi:10.1016/S1734-1140(11)70719-8

68. Liem-Moolenaar M, Rad M, Zamuner S, et al. Central nervous system effects of the interaction between risperidone (single dose) and the 5-HT6 antagonist SB742457 (repeated doses) in healthy men. Br J Clin Pharmacol. 2011;71(6):907-916. doi:10.1111/j.1365-2125.2011.03902.x

69. Hughes AM, Lynch P, Rhodes J, et al. Electroencephalographic and psychomotor effects of chlorpromazine and risperidone relative to placebo in normal healthy volunteers. Br J Clin Pharmacol. 1999;48 (3):323-330. doi:10.1046/j.1365-2125.1999.00021.x

70. Artaloytia JF, Arango C, Lahti A, et al. Negative signs and symptoms secondary to antipsychotics: a double-blind, randomized trial of a single dose of placebo, haloperidol, and risperidone in healthy volunteers. $\mathrm{Am}$ J Psychiatry. 2006;163(3):488-493. doi:10.1176/appi.ajp.163.3.488

71. Barrett SL, Bell R, Watson D, King DJ. Effects of amisulpride, risperidone and chlorpromazine on auditory and visual latent inhibition, prepulse inhibition, executive function and eye movements in healthy volunteers. $J$ Psychopharmacol. 2004;18(2):156-172. doi: $10.1177 / 0269881104042614$

72. Libman-Sokołowska M, Drozdowicz E, Nasierowski T. BDNF as a biomarker in the course and treatment of schizophrenia. Psychiatr Pol. 2015;49(6):1149-1158. doi:10.12740/pp/37705

73. Zhang J, Yao W, Hashimoto K. Brain-derived neurotrophic factor (BDNF)-TrkB signaling in inflammation-related depression and potential therapeutic targets. Curr Neuropharmacol. 2016;14:721-731. doi:10.2174/1570159X14666160119094

74. Duman CH, Schlesinger L, Kodama M, Russell DS, Duman RSA. Role for MAP kinase signaling in behavioral models of depression and antidepressant treatment. Biol Psychiatry. 2007;61(5):661-670. doi:10.1016/j.biopsych.2006.05.047
75. Chang H-A, Fang W-H, Liu Y-P, et al. BDNF Val ${ }^{66}$ Met polymorphism to generalized anxiety disorder pathways: indirect effects via attenuated parasympathetic stress-relaxation reactivity. $J$ Abnorm Psychol. 2020;129(3):237-247. doi:10.1037/abn0000507

76. Shirayama Y, Chen ACH, Nakagawa S, Russell DS, Duman RS. Brain-derived neurotrophic factor produces antidepressant effects in behavioral models of depression. $J$ Neurosci. 2002;22(8):3251-3261. doi:10.1523/JNEUROSCI.22-08-03251.2002

77. Castrén E. Neurotrophins and psychiatric disorders. In: Lewin GR, Carter BD, editors. Handbook of Experimental Pharmacology. Vol. 220. Berlin Heidelberg: Springer; 2014:461-479. doi:10.1007/9783-642-45106-5_17.

78. Deltheil T, Guiard BP, Cerdan J, et al. Behavioral and serotonergic consequences of decreasing or increasing hippocampus brain-derived neurotrophic factor protein levels in mice. Neuropharmacology. 2008;55(6):1006-1014. doi:10.1016/j.neuropharm.2008.08.001

79. Hashimoto K. Brain-derived neurotrophic factor as a biomarker for mood disorders: an historical overview and future directions. Psychiatry Clin Neurosci. 2010;64(4):341-357. doi:10.1111/j.14401819.2010.02113.x

80. Popova NK, Ilchibaeva TV, Naumenko VS. Neurotrophic factors (BDNF and GDNF) and the serotonergic system of the brain. Biochem. 2017;82(3):308-317. doi:10.1134/S0006297917030099

81. Agostinho FR, Réus GZ, Stringari RB, et al. Olanzapine plus fluoxetine treatment increases Nt-3 protein levels in the rat prefrontal cortex. Neurosci Lett. 2011;497(2):99-103. doi:10.1016/j.neulet.20 11.04.039

82. Zhang W, Perry KW, Wong DT, et al. Synergistic effects of olanzapine and other antipsychotic agents in combination with fluoxetine on norepinephrine and dopamine release in rat prefrontal cortex. Neuropsychopharmacology. 2000;23(3):250-262. doi:10.1016/S089 3-133X(00)00119-6

83. Ichikawa J, Kuroki T, Dai J, Meltzer HY. Effect of antipsychotic drugs on extracellular serotonin levels in rat medial prefrontal cortex and nucleus accumbens. Eur J Pharmacol. 1998;351(2):163-171. doi:10.1016/S0014-2999(98)00308-2

84. Rogóż Z. Combined treatment with atypical antipsychotics and antidepressants in treatment-resistant depression: preclinical and clinical efficacy. Pharmacol Reports. 2013;65(6):1535-1544. doi:10.1016/ S1734-1140(13)71515-9

85. Wesołowska A. Study into a possible mechanism responsible for the antidepressant-like activity of the selective 5-HT6 receptor antagonist SB-399885 in rats. Pharmacol Rep. 2007;59(6):664-671.

86. Jastrzębska-Więsek M, Siwek A, Partyka A, et al. Study of a mechanism responsible for potential antidepressant activity of EMD 386088, a 5-HT6 partial agonist in rats. Naunyn Schmiedebergs Arch Pharmacol. 2016;389(8):839-849. doi:10.100 7/s00210-016-1245-3

87. Blin O, Azorin JM, Bouhours P. Antipsychotic and anxiolytic properties of risperidone, haloperidol, and methotrimeprazine in schizophrenic patients. J Clin Psychopharmacol. 1996;16(1):38-44. doi:10.1097/00004714-199602000-00007

88. Sheehan DV, McElroy SL, Harnett-Sheehan K, et al. Randomized, placebo-controlled trial of risperidone for acute treatment of bipolar anxiety. $J$ Affect Disord. 2009;115(3):376-385. doi:10.1016/j. jad.2008.10.005

89. Padala PR, Madison J, Monnahan M, et al. Risperidone monotherapy for post-traumatic stress disorder related to sexual assault and domestic abuse in women. Int Clin Psychopharmacol. 2006;21(5):275-280. doi:10.1097/00004850-200609000-00005

90. Robinson DG, Gallego JA, John M, et al. A potential role for adjunctive omega-3 polyunsaturated fatty acids for depression and anxiety symptoms in recent onset psychosis: results from a 16 week randomized placebo-controlled trial for participants concurrently treated with risperidone. Schizophr Res. 2019;204(5):295-303. doi:10.1016/j.schres.2018.09.006 


\section{Publish your work in this journal}

Neuropsychiatric Disease and Treatment is an international, peerreviewed journal of clinical therapeutics and pharmacology focusing on concise rapid reporting of clinical or pre-clinical studies on a range of neuropsychiatric and neurological disorders. This journal is indexed on PubMed Central, the 'PsycINFO' database and CAS, and is the official journal of The International Neuropsychiatric Association (INA). The manuscript management system is completely online and includes a very quick and fair peer-review system, which is all easy to use. Visit http://www.dovepress.com/testimonials.php to read real quotes from published authors.

Submit your manuscript here: https://www.dovepress.com/neuropsychiatric-disease-and-treatment-journal 